\title{
COVID-19 vaccines: rapid development, implications, challenges and future prospects
}

\author{
Shivaji Kashte ${ }^{1} \cdot$ Arvind Gulbake $^{2}$ Saadiq F. El-Amin IIII,4 Ashim Gupta $^{4,5,6,7}$ (I)
}

Received: 10 February 2021 / Accepted: 17 February 2021 / Published online: 7 March 2021

(c) The Author(s) 2021

\begin{abstract}
COVID-19 has affected millions of people and put an unparalleled burden on healthcare systems as well as economies throughout the world. Currently, there is no decisive therapy for COVID-19 or related complications. The only hope to mitigate this pandemic is through vaccines. The COVID-19 vaccines are being developed rapidly, compared to traditional vaccines, and are being approved via Emergency Use Authorization (EUA) worldwide. So far, there are 232 vaccine candidates. One hundred and seventy-two are in preclinical development and 60 in clinical development, of which 9 are approved under EUA by different countries. This includes the United Kingdom (UK), United States of America (USA), Canada, Russia, China, and India. Distributing vaccination to all, with a safe and efficacious vaccine is the leading priority for all nations to combat this COVID-19 pandemic. However, the current accelerated process of COVID-19 vaccine development and EUA has many unanswered questions. In addition, the change in strain of SARS-CoV-2 in UK and South Africa, and its increasing spread across the world have raised more challenges, both for the vaccine developers as well as the governments across the world. In this review, we have discussed the different type of vaccines with examples of COVID-19 vaccines, their rapid development compared to the traditional vaccine, associated challenges, and future prospects.
\end{abstract}

Keywords SARS-Cov-2 $\cdot$ COVID-19 $\cdot$ COVID-19 vaccine $\cdot$ Vaccine hesitancy $\cdot$ Emergency use authorization

Arvind Gulbake

arvind.gulbake@gmail.com

$\triangle$ Ashim Gupta

ashim6786@gmail.com

Shivaji Kashte

kashtesb@gmail.com

Saadiq F. El-Amin III

dr.saadiqelamin@gmail.com

1 Department of Stem Cell and Regenerative Medicine, Center for Interdisciplinary Research, D.Y. Patil Education Society (Institution Deemed To Be University), Kolhapur, Maharashtra 416006, India

2 Dehradun Institute of Technology (DIT) University, Dehradun, Uttarakhand 248009, India

3 El-Amin Orthopaedic and Sports Medicine Institute, Lawrenceville, GA 30043, USA

4 BioIntegrate, Lawrenceville, GA 30043, USA

5 South Texas Orthopaedic Research Institute, Laredo, TX 78045, USA

6 Veterans in Pain, Valencia, CA 91354, USA

7 Future Biologics, Lawrenceville, GA 30043, USA

$\begin{array}{ll}\text { Abbreviations } \\ \text { SARS-Cov-2 } & \begin{array}{l}\text { Severe acute respiratory syndrome corona- } \\ \text { virus 2 }\end{array} \\ \text { Covid-19 } & \begin{array}{l}\text { Coronavirus disease 2019 } \\ \text { WHO }\end{array} \\ \text { WK } & \text { World Health Organization } \\ \text { USA } & \text { United Kingdom } \\ \text { CVCs } & \text { COVIted States of America } \\ \text { EUA } & \text { Emergency Use Authorization } \\ \text { TLRs } & \text { Toll-like receptors } \\ \text { FDA } & \text { Food and Drug Administration } \\ \text { RBD } & \text { Receptor-binding domain } \\ \text { TGA } & \text { Australian Therapeutic Good } \\ & \text { Administration } \\ \text { MHRA } & \text { The Medicines and Healthcare products } \\ & \text { Regulatory Agency } \\ \text { UAE } & \text { United Arab Emirates } \\ \text { ICMR } & \text { Indian Council of Medical Research } \\ \text { CDC } & \text { Centers for Disease Control and Prevention } \\ \text { VAERD } & \text { Vaccine-enhanced disease for inactivated } \\ & \text { vaccine candidates } \\ \text { VCD } & \text { Virologically confirmed dengue }\end{array}$




$\begin{array}{ll}\text { DCVMN } & \begin{array}{l}\text { Developing Countries Vaccine Manufac- } \\ \text { turers Network } \\ \text { Global Alliance for Vaccines and }\end{array} \\ \text { GAVI } & \begin{array}{l}\text { Immunizations } \\ \text { GVAP }\end{array} \\ \text { Global Vaccine Action Plan } \\ \text { Coalition for Epidemic Preparedness } \\ \text { Innovations } \\ \text { COVAX } & \text { COVID-19 Vaccine Global Access Facility }\end{array}$

\section{Background}

Severe acute respiratory syndrome coronavirus 2 (SARSCov-2) infections and the resulting diseases, coronavirus disease 2019 (COVID-19) have spread to millions of people worldwide. The World Health Organization (WHO) declared the COVID-19, a pandemic in March 2020 [1]. The SARS-CoV-2 has affected over 105 million people and has claimed over 2.29 million lives worldwide, as of February 5,2021 . The most affected countries have been the United States of America, with over 26.7 million cases and 456,000 deaths, and India, with over 10.8 million cases and 155,000 deaths as of February 5, 2021 [2]. COVID-19 has negatively impacted the health and lifestyle of people as well as the economy throughout the world [3]. An intensive search for an effective drug against the SARS-CoV-2 did not lead to any breakthrough candidates. The drugs like Hydroxychloroquine and Remdesivir were advocated as desperate measures based on contradictory and inconclusive studies and have significantly failed to combat the pandemic [4]. As the number of COVID-19 patients continues to increase, detecting, assessing, and interpreting the immune response to SARS-CoV-2 infection becomes essential. Multiple vaccine candidates are under development but safe and effective vaccines against COVID-19 are urgently needed to combat escalating cases and deaths worldwide. These vaccine candidates need to be manufactured as soon as possible and made available to all countries and populations affected by the pandemic at an affordable price. A vaccine has the ability to induce herd immunity in societies, which can decrease the occurrence of the disease, block transmission, and reduce the social and economic burden of the disease.

On December 2, 2020, United Kingdom (UK) became the first country to approve the COVID-19 vaccine, BNT162, developed by Pfizer and BioNTech via Emergency Use Authorization (EUA). WHO approved BNT162 for emergency use on December 31, 2020 to allow for easier global manufacturing and distribution. Similar EUA processes were adapted by several countries including, United States, Canada, Russia, China, and India to approve different COVID19 vaccine candidates (CVCs) and the list is growing. There are a total of 232 vaccine candidates at various stages of development, of which 172 are in preclinical development,
60 are in clinical development, and 9 are approved under EUA by different countries (Tables 1 and 2) [5]. Despite the rollout of these vaccines under EUA, several questions need to be answered. How are these vaccines developed so rapidly? Are these vaccines safe and efficacious? How long the efficacy will last? What are potential threats? What are challenges? Are they effective against changing strains of virus? In this review, we will discuss and emphasize the vaccines approved via EUA and the ones that have entered Phase III clinical trials and have demonstrated the potential to be approved.

\section{What is a vaccine?}

"Vaccines are biologics that provide active adaptive immunity against specific diseases" [5]. Vaccine development involves utilizing the microorganisms responsible for the disease either in the killed or attenuated form, or it involves the use of microorganisms' toxins or surface proteins. The vaccines are introduced in the body via mouth, injection or by nasal route to incite the immune system against foreign bodies [6].

In the process of immunity development, the body produces antibodies against specific microorganisms, which generates the defense mechanism. When a person encounters the same microorganisms later, the antibodies produced by the body in response to the microorganisms' antigens either prevents the person from the disease induced by the microorganism or lessens the severity of the disease [6]. Vaccines, in general, are considered the most economical healthcare interventions and its said that "A dollar spent on a childhood vaccination not only helps save a life but greatly reduce spending on future healthcare" $[6,7]$.

\section{What are different types of vaccines?}

There are different types of vaccines including live attenuated, inactivated, protein-based, nucleic acid, and viral vector-based. Each type of vaccine has a subtle structure, advantages and disadvantages with respect to immunogenicity, safety, ease of use and effectiveness.

\section{Live attenuated vaccines}

"Live attenuated vaccines are viruses weakened by passing through animal or human cells, until genome mutates and is unable to cause disease" [7]. The attenuated virus replicates like a natural infection and causes strong $\mathrm{T}$ cell and B cell immune responses [7]. Live attenuated vaccines have the inherent ability to induce toll-like receptors (TLRs) such as TLR 3, TLR 7/8, and TLR 9 of the innate immune 


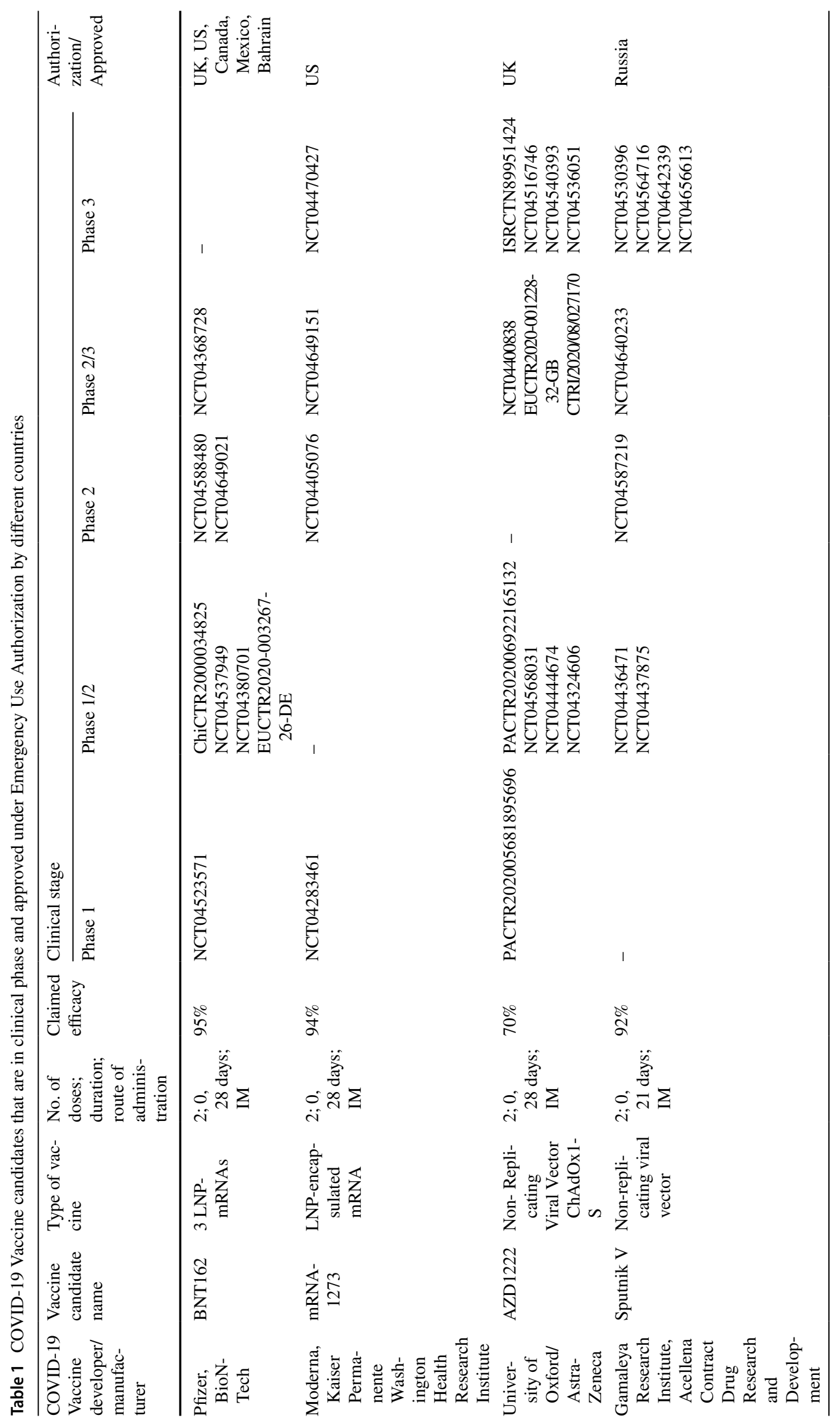




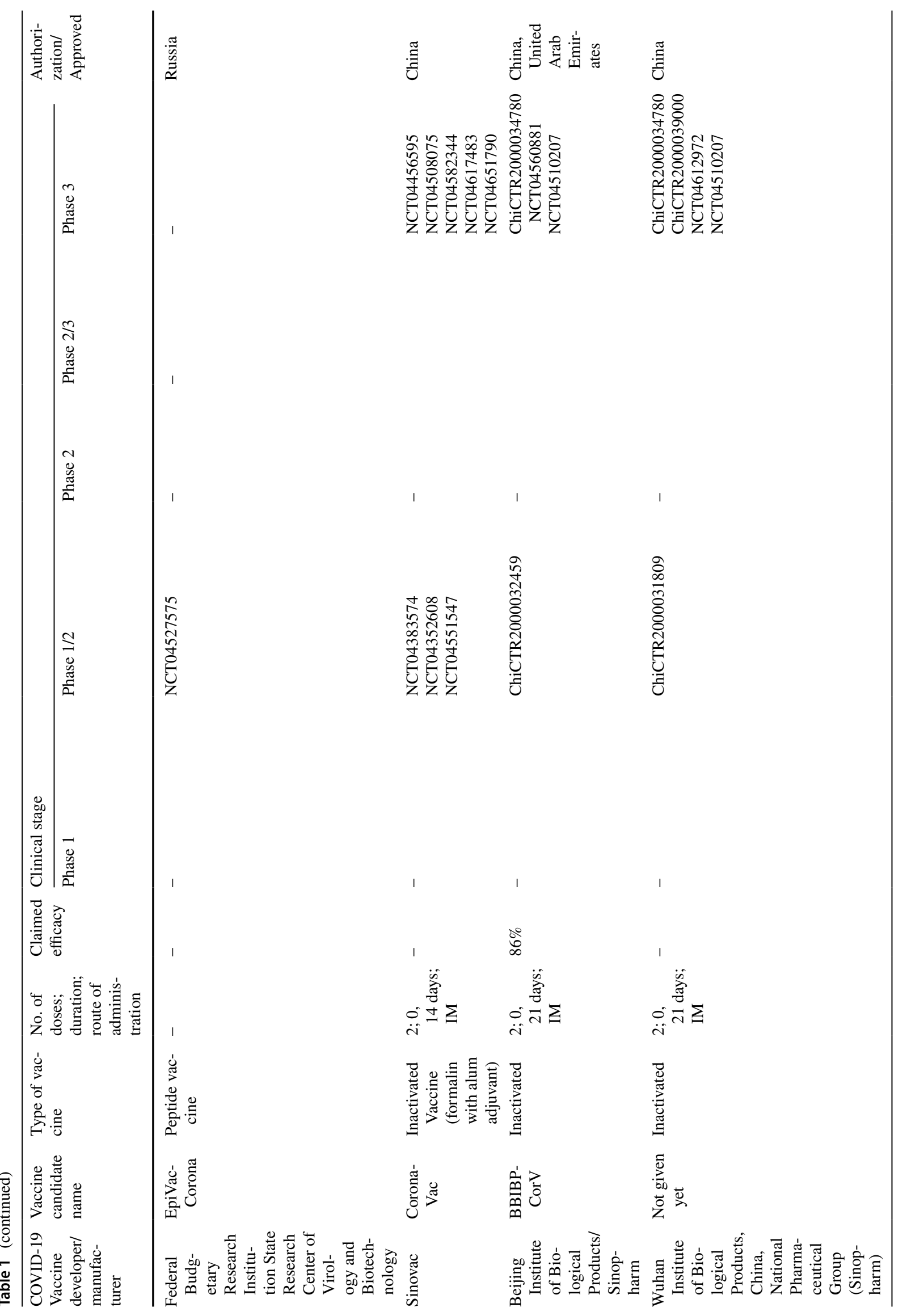




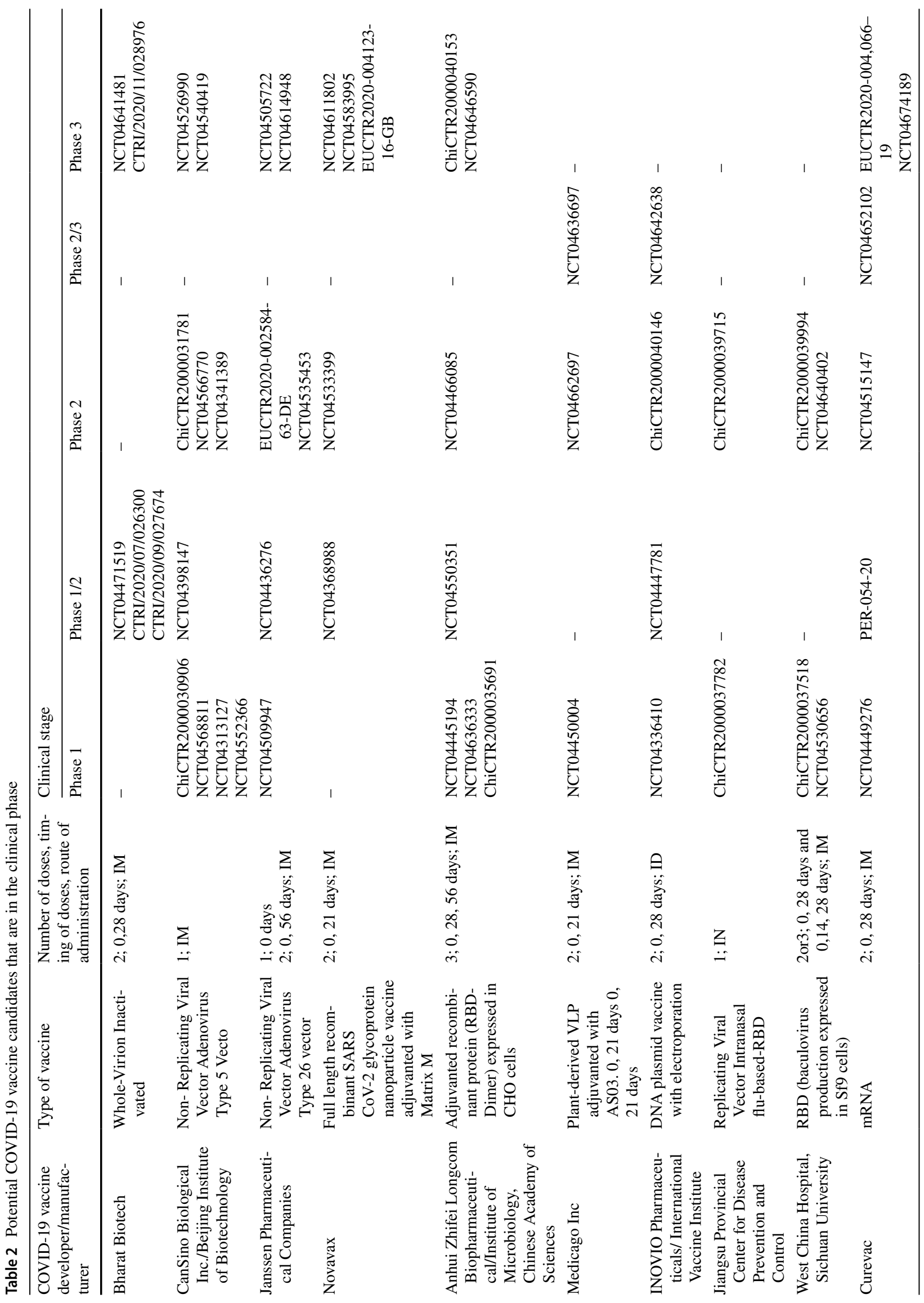




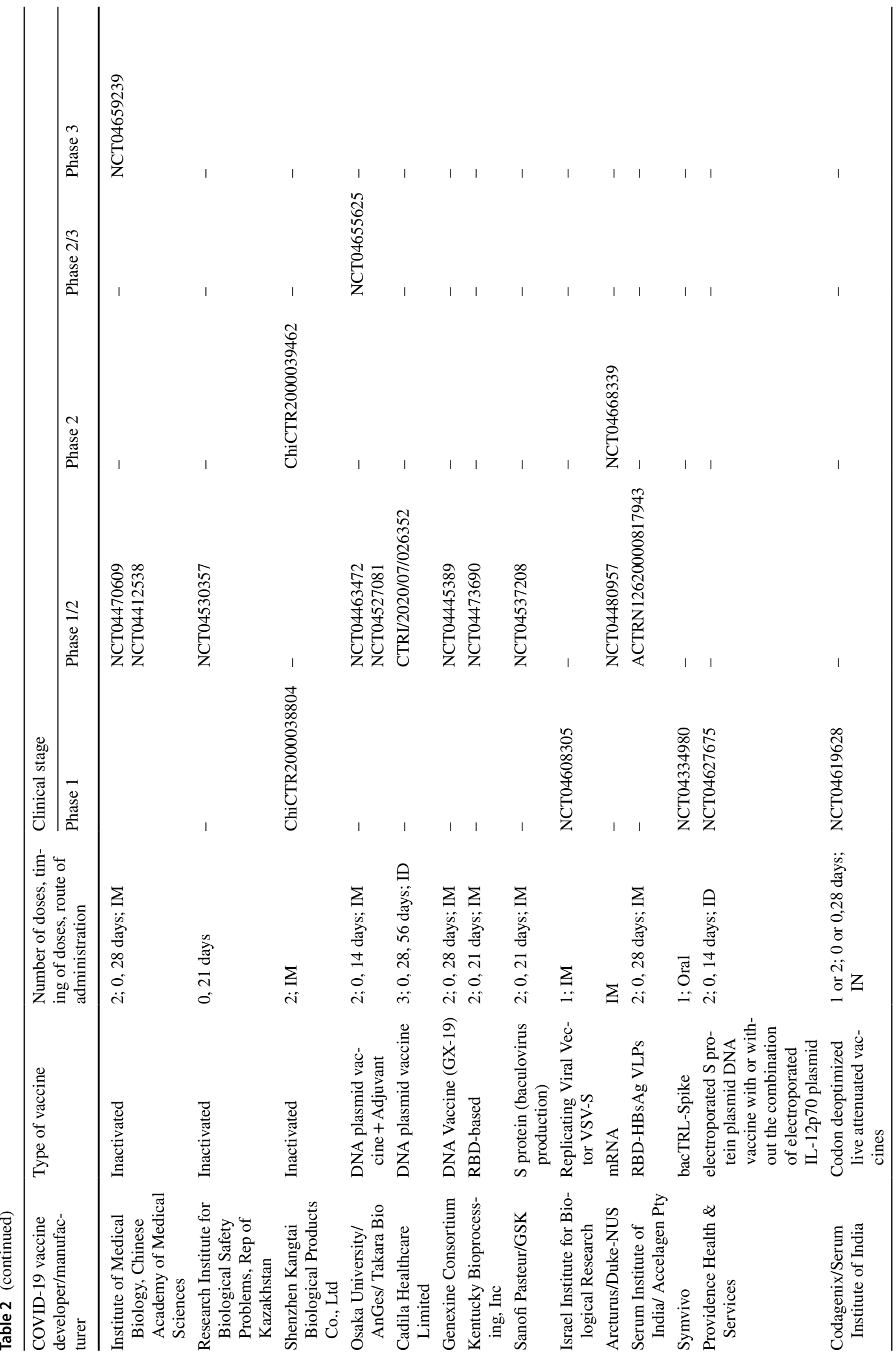




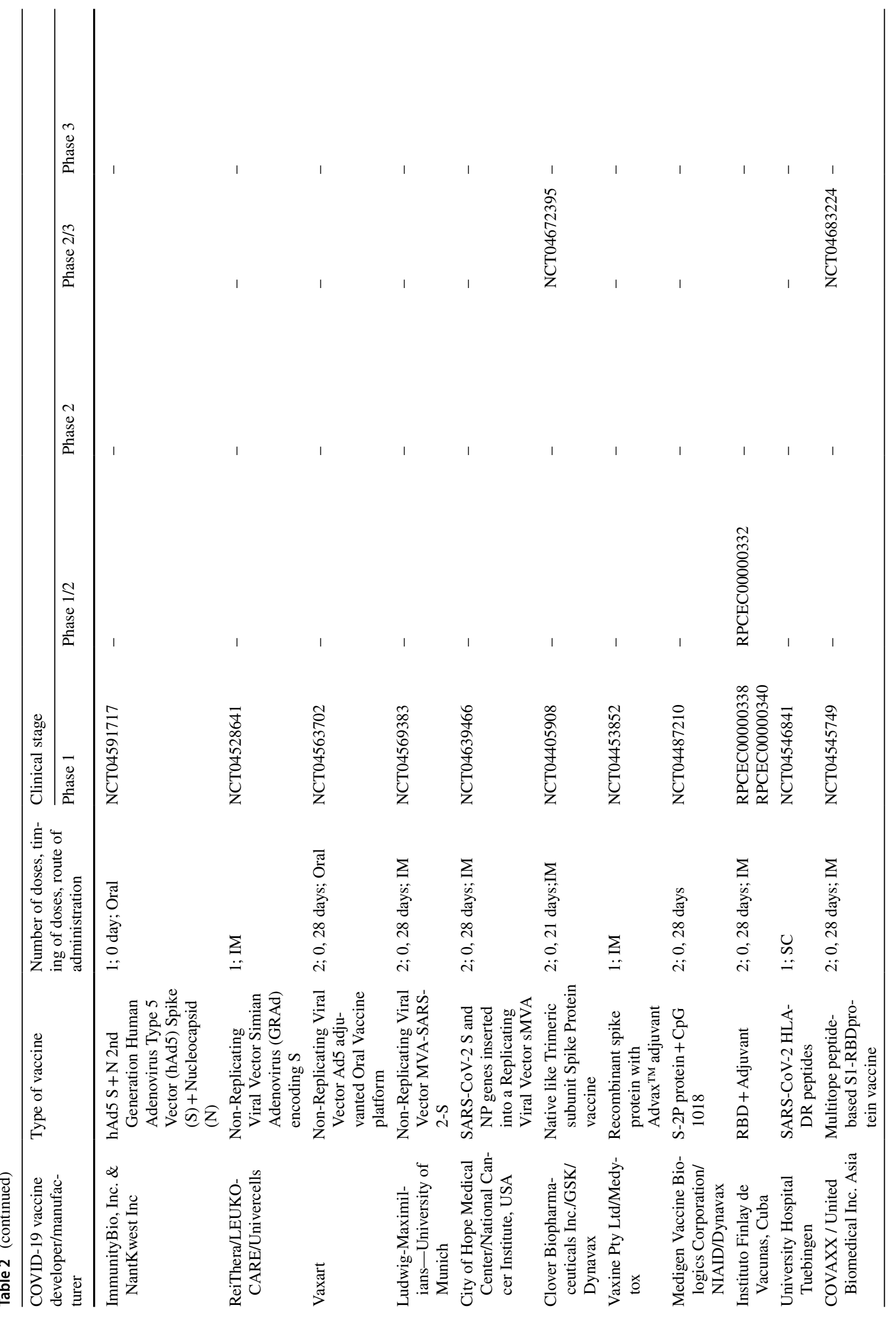




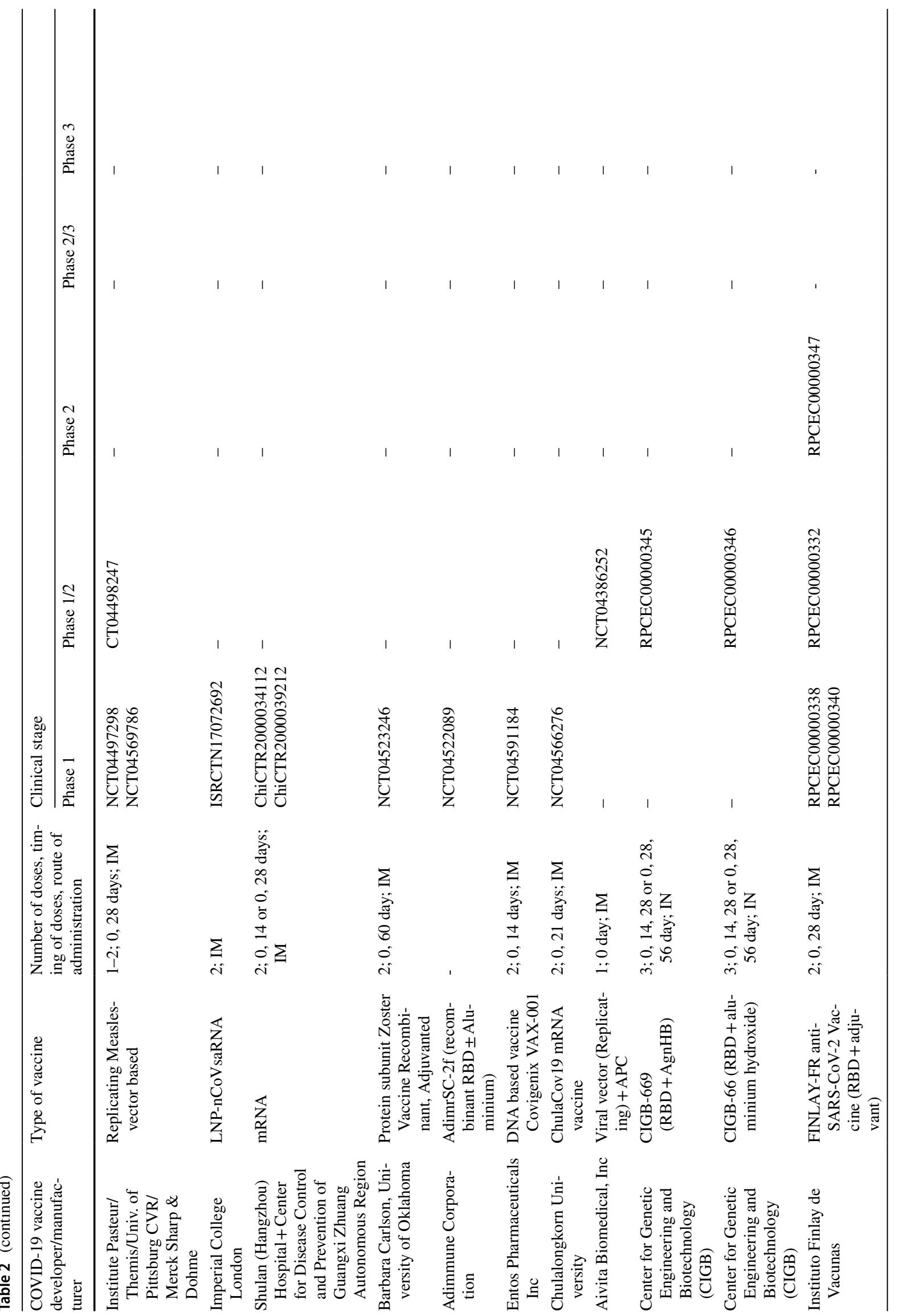




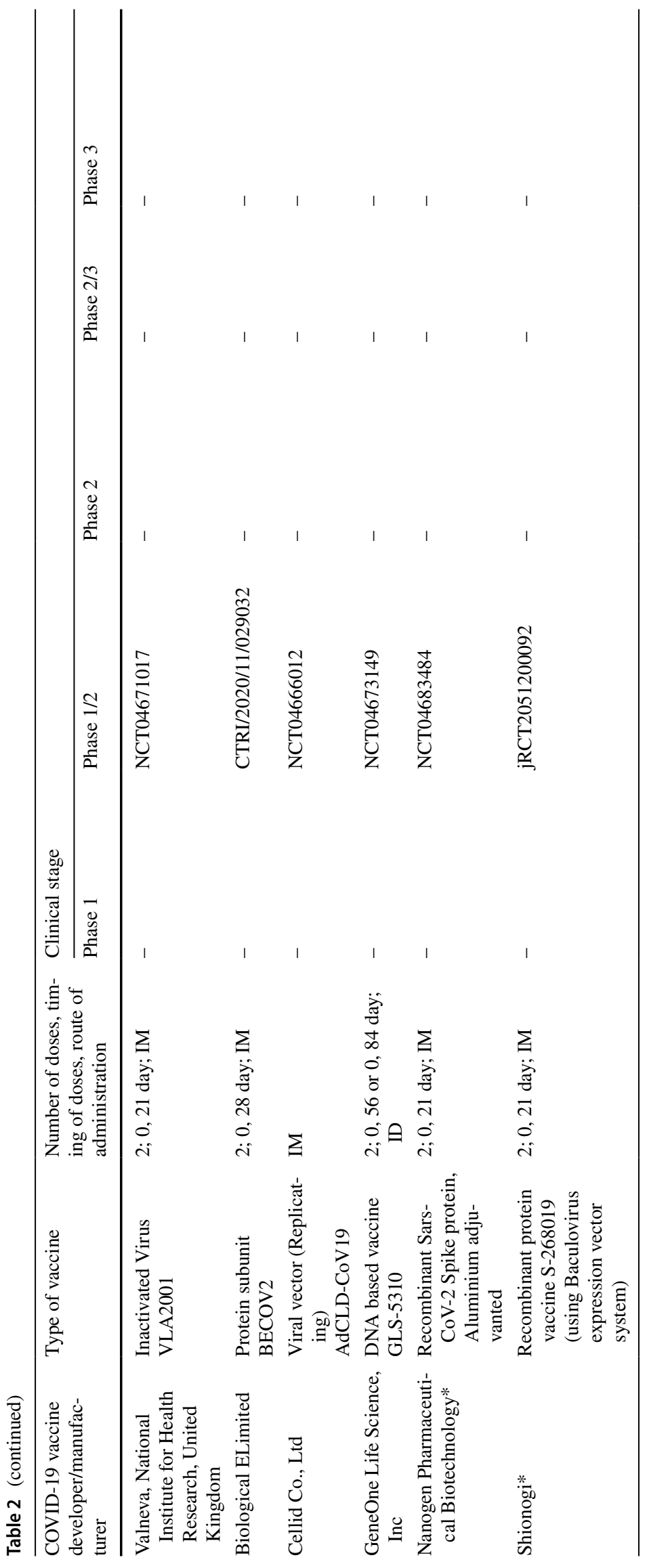


system that involves B cells, CD4 and CD8 T cells. They can be obtained from 'cold adapted' virus strains, reassortments, and reverse genetics; and can be low-cost and rapidly produced [7]. Herd immunity can be achieved through these vaccines in the community [7]. Broad adjunct testing is required to confirm their safety and efficacy. There is also a possibility of mutations during viral replication which may lead to recombinants post-vaccination [8]. In addition, cold chain distribution in the community is required. Some examples of live attenuated vaccines include BCG, Smallpox, and Polio (OPV) [7]. An example of such vaccine to mitigate COVID-19 is DelNS1-SARS-CoV2-RBD, by University of Hong Kong [7].

\section{Inactivated vaccines}

These are inactivated viruses developed using formaldehyde or heat. They do not have any live component of the viral particles [8]. These are noninfectious, stable, and safer compared to a live attenuated vaccine [8]. These vaccines can be freeze-dried and do not require cold chains for distribution [7]. Such vaccines do not replicate and have a suboptimum immune response. They can be used along with adjuvants to increase their immunogenicity. As large quantities of viruses need to be handled while maintaining their integrity [6-8], there are chances of Th2 cell skewed response (antibodydependent enhancement, ADE). Some examples of inactivated vaccines include Hepatitis A and Rabies. An example of such a vaccine to mitigate COVID-19 is PiCoVacc, by Sinovac Biotech.

\section{Protein-based vaccines}

\section{Protein sub-unit}

These are antigenic components [spike (S) protein] generated in vitro. They do not have any live components of the viral particle. They are considered safe and have less adverse effects. They exhibit low immune response, therefore, need multiple dosing and adjuvants. Even memory for future responses is doubtful [6-8]. The S protein of the SARS$\mathrm{CoV}-2$ is the most suitable antigen to induce the neutralizing antibodies against the pathogen [9]. One of the examples of such a vaccine to mitigate COVID-19 is NVX-CoV2373, by Novavax [7].

\section{Virus-like particles}

These are empty virus shells without genetic material. They are considered safe, induce a strong immune response, and are difficult to manufacture $[7,8]$. One example of such a vaccine to mitigate COVID-19 is Triple-Antigen Vaccine, by Premas Biotech [7].

\section{Nucleic acid vaccines: new generation vaccines}

\section{DNA vaccines}

These vaccines are made by introducing DNA encoding the antigen from the pathogen into a plasmid (antigenic components of SARS-CoV-2 such as spike protein). These are considered safe, unable to cause disease. These types of vaccines are unproven in practice. They can cause adverse events (ADE) when used alone [6-8]. These vaccines are highly immunogenic; generate a high titer of neutralizing antibodies when given with inactivated vaccine. An electroporation device is needed to deliver these vaccines. One example of such a vaccine to mitigate COVID-19 is INO4800 , by INOVIO Pharma, Korean Institute of Health, and International Vaccine Institute [8].

\section{RNA vaccines}

RNA vaccines are lipid-coated mRNA of the SARS-CoV-2 expressing spike protein. These are considered safe and unable to cause disease, but are able to induce ADE and are unproven in practice [6, 7]. Examples of such vaccines to mitigate COVID-19 are mRNA-1273, by Moderna; and BNT162 (a1, b1, b2, c2), by BioNTech/Fosun Pharma/Pfizer [8].

\section{Viral vector vaccines}

Recombinant DNA technology is used to create these vaccines. The DNA encoding an antigen from the pathogen is inserted into the bacteria or virus vectors. These bacteria or virus vectors then express the antigen in these cells. The antigens are harvested and then purified from the bacteria or virus vectors. Viral vector vaccines could be replicating or nonreplicating.

\section{Replicating}

An unrelated virus-like measles or adenovirus is genetically engineered to encode the gene of interest. These are considered safe and are able to induce strong $\mathrm{T}$ cell and $\mathrm{B}$ cell response. Some examples of such vaccines include Hepatitis $\mathrm{B}, \mathrm{HPV}$, and pertussis [6-8].

\section{Nonreplicating}

An unrelated virus, like measles or adenovirus (with the inactive gene), is genetically engineered to encode the gene of interest. These are considered safe and require booster doses to induce long-term immunity. These types of vaccines are not licensed yet $[6,7]$. Examples of such vaccines to mitigate COVID-19 are Ad5-nCoV by CanSino Biological Inc./ 
Beijing Institute of Biotechnology; and ChAdOx-nCoV-19 by the University of Oxford [8].

\section{How COVID-19 vaccines are developed rapidly as compared to traditional vaccines?}

Vaccine development is a complex multidisciplinary activity, blending knowledge of host-pathogen interactions with clinical science, population-level epidemiology, and the biomechanical requirements of production. The core is an insight into immune processes that influence the disease and protection and their variation between individuals, risk groups, and populations [10]. Traditional vaccine development (Fig. 1) has been a complex and time-consuming process that typically takes around $10-15$ years. Vaccine development usually begins with an exploratory stage focusing on basic research and computational modeling to find out potential natural or synthetic antigens as a vaccine candidate. After this, a pre-clinical study (18-30 months) starts with cell-culture followed by animal studies to analyze the safety and immunogenic potential of the vaccine candidate. After appropriate in vivo results on safety, immunogenicity, and efficacy, human clinical trials initiated for safety and immunogenicity in small groups, and later in the large groups over 3 phases (Phase 1 or I, 2 or II and 3 or III).

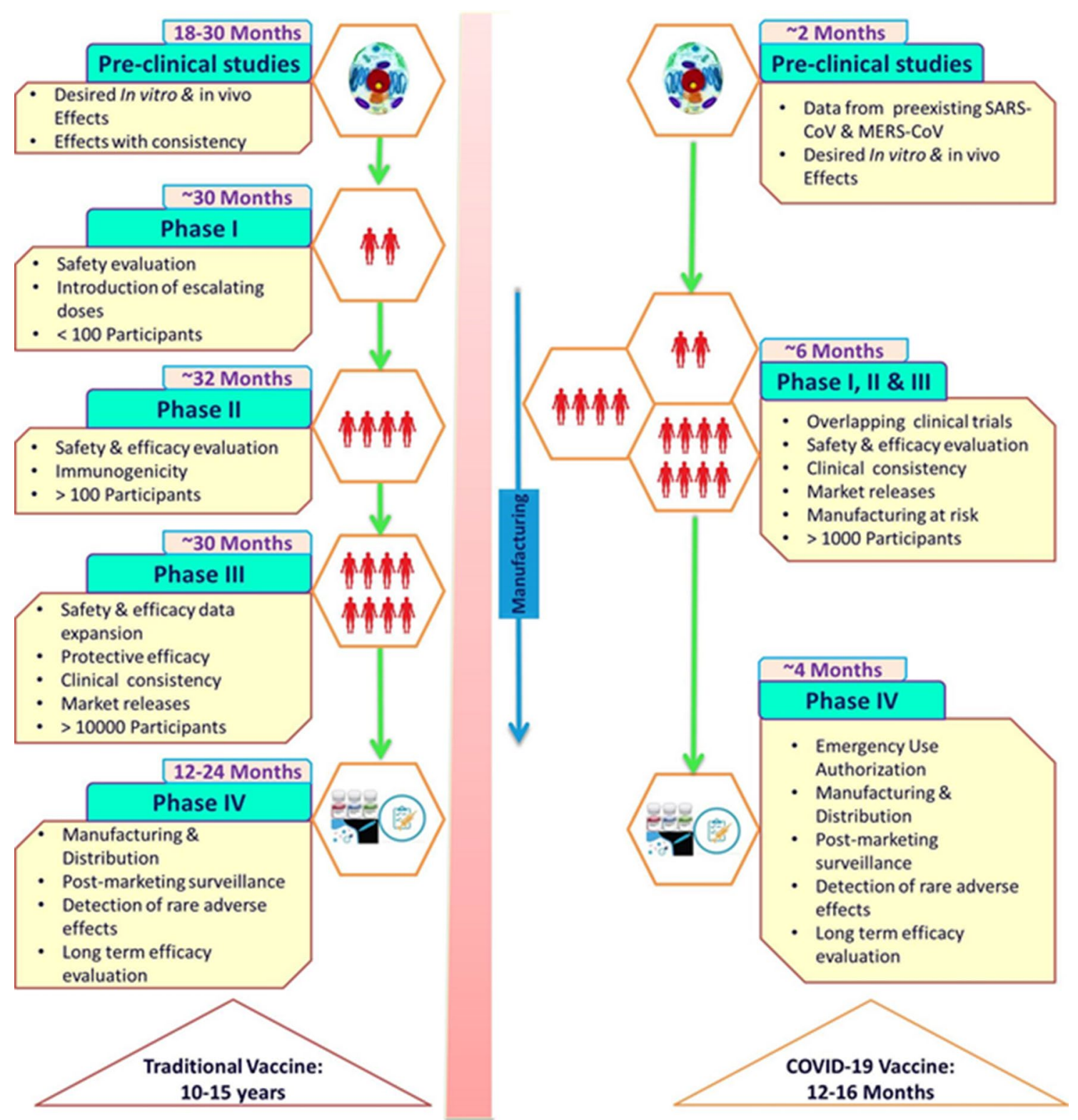

Fig. 1 Rapid development of COVID-19 vaccine as compared to traditional vaccine development. Adapted from Calina et al. [76] 
The primary goal of Phase 1 trial ( 30 months) is to assess the safety and immunogenicity of the vaccine candidate. In Phase 1 trial, the vaccine is administered to less than a hundred healthy participants. If promising results are obtained in Phase 1, Phase 2 trial ( 32 months) is carried out in more than a hundred participants, divided into multiple groups by demographics. The goal of the phase 2 trial is to confirm the safety and immunogenicity of vaccine candidates. Also, the suitable dose required for Phase 3 is calculated. If encouraging results in Phase II trials are obtained, Phase 3 trial ( $\sim 30$ months) is then carried out in thousands of participants to evaluate the efficacy. "Incidence of disease at the time of phase 3 trials impacts the sample size" [11]. If there is a low incidence of disease in the community, large sample size will be required to satisfactorily decide the vaccine efficacy. After completion of these trials, safety and the clinical efficacy are calculated, then the vaccine is reviewed for approval by regulatory bodies, such as Food and Drug Administration (FDA) of the United States of America (USA), or the European Medicines Agency in European Union (EU). Later, manufacturing and post-marketing surveillance are done after the vaccine is marketed for public use and monitored for general effectiveness within the population. Even after the vaccine is adopted for widespread use, events of adverse effects are recorded. The developer advances the vaccine development only if the data is promising, the risk of failure is relatively low and there is a market for the vaccine [11].

The mumps was the only fastest developed and approved vaccine for use, taking about 5 years. Even with this experience, it is clearly a big challenge to develop a vaccine against COVID-19 in a span of 12-24 months. COVID-19 vaccine development (Fig. 1) has targeted to significantly reduce this 10-15-year timeline to 12-24 months. The initial process started as soon as the genome sequence of SARS-CoV-2 was available. The significant amount of time was saved by using the data from the preclinical development of vaccine candidates for SARS-CoV and MERS-CoV and omitting the initial step of the exploratory phase. Some vaccine candidates used modified production processes from those of existing vaccine candidates while others used preclinical and toxicology data from related vaccines. Therefore, the first clinical trial of CVCs started in March 2020 (NCT04283461) [11]. Clinical trials were designed to reduce the time horizon by overlapping clinical trial phases. The initial phase I/II trials were followed by rapid advancement to phase III trials as soon as the interim analysis of the phase I/II data was completed. The US accelerated the development of five CVCs under the Operation Warp Speed to make them available by the end of 2020 for emergency use and have billions of doses ready by 2021 [11]. Manufacturers prepared themselves to rapidly produce billions of doses and few of them already started the commercial production of vaccines without any results from phase III trials. The review process is expedited via Emergency Use Authorization (EUA) by countries like UK, USA and subsequently followed by many more. The challenging task of developing CVCs is achieved in record time frame of 12-16 months as compared to traditional vaccine development taking 10-15 years (Fig. 1) [12].

\section{COVID-19 vaccines approved through Emergency Use Authorization}

Vaccines traditionally used are live attenuated viruses, inactivated viruses, protein or polysaccharide conjugated subunit vaccines and virus-like particles. Also, recently included vaccines are nucleic acids, DNA and RNA and viral vectors and recombinant proteins.

SARS-CoV-2 induces a strong adaptive immune response of both T and B cell. Additionally, antibodies IgG and IgM appear about 10 days post-infection. The majority of the patients are able to seroconvert in 3 weeks. The antibodies are created against internal nucleoprotein $(\mathrm{N})$ and spike protein (S) of the virion and possess neutralizing activity. Antibodies which bind to the spike protein, particularly to its receptor-binding domain (RBD), inhibit its attachment to the host cell and counteract the virus [13]. Table 1 lists few vaccine candidates approved through EUA that reached up to or completed Phase 3 trials.

\section{BNT162 vaccine by Pfizer and BioNTech}

On December 2, 2020, UK became the first country to approve COVID-19 vaccine BNT162 developed by Pfizer and BioNTech via EUA. On December 11, 2020 US FDA issued first EUA for BNT162 having demonstrated 95\% efficacy in preventing disease in phase III clinical trial results [14]. Later Canada and Mexico also approved BNT162 via respective EUA pathways. On December 31, 2020, WHO approved first vaccine candidate, BNT162, for emergency use thereby making it easier to manufacture and distribute this vaccine globally [15]. Initially, four candidates were developed of which two were nucleoside modified mRNA, modRNA; one was uridine containing mRNA, uRNA; and other was self-amplifying mRNA, saRNA. In the preclinical study, modRNA BNT162b2 showed protective antiviral effects in Rhesus macaques with concurrent elevated neutralizing antibody titers and a Th-1 biased cellular response in Rhesus macaques, as well as in mice. Therefore, BNT162b2 was selected for Phase 2/3 clinical trials [16].

In Phase 1/2 trial of two hundred participants aged $18-55$ years with a vaccine dose range of $1-100 \mu \mathrm{g}$ is currently recruiting (NCT04380701) as is a Phase $2 / 3$ trial of about 32,000 participants (NCT04368728) and a Phase 1/2 trial of 160 participants between age 20-85 (NCT04588480) [16].On November 9, 2020, Pfizer and BioNTech declared 
interim results of 94 participants of Phase 3 trial claiming $>90 \%$ efficacy of BNT162b2 against SARS-Cov-2 infection at 7 days after the administration of second dose [16]. Phase 1 trial data showed similar immunogenicity between BNT162b1 and BNT162b2, while BNT162b2 was associated with a lower incidence and severity of systemic reactions than BNT162b1 [17].

Another study of Phase $1 / 2$ data for BNT162b1 (NCT04368728) showed robust immunogenicity at all three doses of $10 \mu \mathrm{g}, 30 \mu \mathrm{g}$ and $100 \mu \mathrm{g}$ among 45 participants, $18-55$ years of age. Adverse reactions were high at the maximum dose and therefore, participants were not given a second dose. Participants who were given two doses between 1 and $50 \mu \mathrm{g}$ of BNT162b1 had vigorous receptor-binding domain (RBD)-specific IgG antibody, T-cell and favorable cytokine responses [18].

Both BNT162b1 and BNT162b2 received the FDA Fast Track designation. But BNT162b2 was preferred over BNT162b1 for Phase 2/3 safety study, based on preclinical and clinical study results. The developers have asked the FDA to consider an expanded protocol for the Phase 3 trial to include up to 44,000 participants. Europeans Medicines Agency (EMA) has initiated a rolling review of BNT162b2 which helped to accelerate its approval [16]. One drawback with this vaccine is that it requires storage at $-80^{\circ}$ to $-60{ }^{\circ} \mathrm{C}$, a fact that could pose logistic problems [19].

\section{mRNA-1273 vaccine by Moderna}

Moderna's mRNA-1273 becomes the second CVC to be approved by FDA under EUA. It is developed on the basis of available data of coronaviruses causing severe acute respiratory syndrome (SARS) and the Middle East respiratory syndrome (MERS). A Phase 3 trial of 30,000 participants at higher risk for COVID-19 is ongoing. Participants will be given $100 \mu \mathrm{g}$ dose of mRNA-1273 or placebo and then be followed for up to 24 months (COVE trial; NCT04470427). After successful completion of Phase 1 trial (NCT04283461) of 105 participants, Phase 2 trial of 600 participants evaluating $25 \mu \mathrm{g}, 100 \mu \mathrm{g}$ and $250 \mu \mathrm{g}$ dose levels of the vaccine was carried out (NCT04405076). Then, Phase 3 results of 95 participants after an interim analysis revealed $94.5 \%$ efficiency of the vaccine with no significant safety concerns [20].

The mRNA-1273 effectively produced neutralizing antibody titers in 8 participants of Phase 1 trial after receiving $25 \mu \mathrm{g}$ or $100 \mu \mathrm{g}$ doses. Neutralizing antibody titers of these participants were similar to the convalescent sera from COVID-19 recuperated patients [21]. Higher age adults subjects who received two doses of either $25 \mu \mathrm{g}$ or $100 \mu \mathrm{g}$ of the mRNA-1273 demonstrated safety and suffered mild or moderate effects including, fatigue, chills, headache, myalgia, and pain at the injection site [22]. In a preclinical study, mRNA-1273 prevented viral replication in the lungs and produced neutralized titers similar to subjects receiving $25 \mu \mathrm{g}$ or $100 \mu \mathrm{g}$ doses of the vaccine [23]. Another preclinical study consisting of nonhuman primates challenged with SARS-CoV-2 showed neutralizing activity and reduced inflammation and lung activity post administration of mRNA-1273 [24].

The mRNA-1273 also got the Fast Track designation from the US FDA. A Phase 3 trial of the vaccine is currently underway and is funded by the Operation Warp Speed [25]. One potential issue for this vaccine could be the storage temperature requirement of $-25^{\circ}$ to $-15^{\circ} \mathrm{C}$ is required [19].

\section{AZD1222 by AstraZeneca and University of Oxford}

On December 30, 2020, UK and on January 2, 2021, India approved AZD1222 COVID-19 vaccine developed by AstraZeneca and the Oxford Vaccine Group at the University of Oxford. It was previously called as ChAdOx1, a chimpanzee adenovirus vaccine $[26,27]$. This group has previously developed a MERS vaccine. In India, this vaccine is jointly developed by Serum Institute of India and AstraZeneca and is branded as Covishield. A preclinical study showed significantly reduced viral load and humoral and cellular immune response [28]. Another preclinical study demonstrated an immune response in both mice and pigs [29]. ChAdOx1, a replication-deficient simian adenoviral vector expressing the full-length SARS-CoV-2 spike (S) protein, was commenced in April 2020 following preclinical studies involving non-human primates using a single dose. When one vs two doses of ChAdOx1 in both mice and pigs were compared, a single dose induced antigen-specific antibody and T cells responses, and a second booster dose enhanced antibody responses, particularly in pigs, with a significant increase in the level of SARS-CoV-2 neutralizing titers [29].

A Phase 1/2 (NCT04324606) study involving 1077 healthy adult participants aged 18-55 years, assessed the safety, reactogenicity, and immunogenicity of a viral vectored coronavirus vaccine, expressing the spike protein of SARS-CoV-2. The results demonstrated an acceptable safety profile for ChAdOx1 $\mathrm{nCoV} 19$ and increased antibody response by homologous boosting [30]. A Phase 3 trial (NCT04516746) is ongoing and has enrolled more than 40,000 subjects. Preliminary results have demonstrated that the safety profile of the vaccine candidate is acceptable, with most patients demonstrating an antibody response after one dose and all patients showing a response after two doses [30]. A Phase 3 trial in Brazil reported one death, which was confirmed by the Brazilian National Health Surveillance Agency (ANVISA). AstraZeneca stated that the results from the Phase 3 trial demonstrate immunogenicity, but have not yet publicly released any data [31]. An inhaled version of the vaccine candidate is also being tested in a small trial involving 30 participants [31]. 
The trials by AstraZeneca are funded by BARDA and Operation Warp Speed. IQVIA also announced they are partnering with AstraZeneca to advance clinical trials for this vaccine. Phase 3 trials are being conducted in the United States and India but were put on hold following reporting of a serious adverse event. Trials have since restarted. Additionally, EMAs human medicines committee (CHMP) and Health Canada have initiated a rolling review of AZD1222 to reduce the decision-making time related to safety and efficacy. The Australian Therapeutic Good Administration (TGA) granted AZD1222 provisional determination, the first step in the approval process. In Britain, the Medicines and Healthcare products Regulatory Agency (MHRA) has also started an accelerated review of AZD1222 [31]. This vaccine requires refrigeration $\left(2-8{ }^{\circ} \mathrm{C}\right)$, which can potentially be problematic for use in low-income countries [19].

\section{CoronaVac by Sinovac}

CoronaVac (formerly PiCoVacc) is approved by China through EUA. CoronaVac is a formalin-inactivated and alum adjuvanted vaccine candidate developed by Sinovac Biotech, China [32]. Results from preclinical studies showed partial or complete protection in non-human primates exposed to SARS-CoV-2 [33].

A Phase $1 / 2$ trial of 743 healthy participants (18-59 years old) who received two different dosages of the vaccine or placebo is active but not recruiting (NCT04551547). A Phase 1 trial of 143 participants (NCT04352608) and Phase 2 trial of 600 participants (NCT04383574) are both active but not recruiting. Phase 3 trial is underway (NCT04456595) to have 9000 participants. Trials are also ongoing in Turkey (NCT04582344) and in Indonesia (NCT04508075). Phase $1 / 2$ trials revealed that the vaccine has good safety and immunogenicity with seroconversion occurring in $92.4 \%$ of participants after the $3 \mu \mathrm{g}$ dose given on a $0-14$ day schedule and $97.4 \%$ of participants with the same dose on a 0-28 day interval [34].

Preliminary results from the Instituto Butantan trial, declared by the Sinovac, showed CoronaVac is safe with no reported serious adverse events. However, the trial in Brazil was briefly suspended due to patient death, though the trial has resumed later [35].

\section{COVID-19 vaccine by Sinopharm and the Wuhan Institute of Virology, China}

China approved this vaccine via EUA. Sinopharm and Wuhan Institute of Virology under the Chinese Academy of Sciences have developed an inactivated CVC [36]. A Phase 1/2 clinical trial (ChiCTR2000031809) involving healthy subjects is ongoing. According to a release from China National Biotec Group, this vaccine has demonstrated a strong neutralizing antibody response. Phase 1 and Phase 2 trials data also showed immunogenicity [37]. A Phase 3 trial is in progress in Peru, Morocco, and United Arab Emirates.

\section{Sputnik V by the Gamaleya Research Institute, Russia}

Russia has approved first CVC as Sputnik V (previously as Gam-COVID-Vac). The Gamaleya Research Institute in Russia and Health Ministry of the Russian Federation are assessing their non-replicating viral vector vaccine, Sputnik $\mathrm{V}$, in a Phase 3 trial. However, there is no trial data available to date. This led to criticism as even there is a lack of data on safety and efficacy, the vaccine is approved.

Two Phase 1/2 trials with 38 subjects each were conducted (NCT04436471, NCT04437875). Sputnik V is additionally being evaluated in a small Phase 2 trial with 110 subjects older than 60 years (NCT04587219). A Phase 3 trial with about 40,000 participants is also in progress (NCT04530396). Aside from Russia, Sputnik V is also being evaluated in Belarus (NCT04564716) and the United Arab Emirates. The results from the Phase 1/2 trials demonstrated the safety and immunogenicity of the vaccine [38]. The Russian Direct Investment Fund also announced that Sputnik V is $92 \%$ effective based on the interim trial results from 20 participants. A preliminary pre-submission of the vaccine has also been proposed in Brazil [39].

\section{BBIBP-CorV by Sinopharm and Beijing Institute of Biological Products, China}

BBIBP-CorV is inactivated CVC developed by Sinopharm in association with Beijing Institute of Biological Products, China. Firstly China and later on United Arab Emirates (UAE) approved the vaccine through EUA [36].

BBIBP-CorV is currently being assessed in Phase 2 (CHiCTR2000032459) and Phase 3 trial in China (ChiCTR2000034780) as well as Phase 3 trial in Argentina (NCT04560881). BBIBP-CorV is shown to be highly effective in preventing disease against SARS-CoV-2 in Rhesus macaques [40]. Phase 1 results showed that BBIBP-CorV was safe and tolerated at all dose levels, with all participants showing a humoral response to the vaccine after 42 days. The UAE announced that the vaccine is $86 \%$ effective [41].

\section{EpiVacCorona by Federal Budgetary Research Institution State Research Center of Virology and Biotechnology, Russia}

Russia also granted regulatory approval to EpiVacCorona, a peptide vaccine candidate for COVID-19, developed by Federal Budgetary Research Institution State Research Center of Virology and Biotechnology [42]. 
A Phase $1 / 2$ trial in Russia is assessing the effectiveness of the vaccine (NCT04527575). A Phase II clinical trial of the vaccine was completed recently. Head of the zoonotic diseases and flu department with the State Research Center of Virology and Biotechnology has said "participants have developed immunity a month after the first vaccination" [43], but there is no data available in the public domain.

\section{Covaxin by Bharat Biotech and National Institute of Virology, India}

On January 2, 2021, India approved an inactivated vaccine called Covaxin, developed by Bharat Biotech and India's National Institute of Virology [27]. A Phase 1/2 trial of about 1100 healthy subjects is ongoing after obtaining permission from the Drug Controller General of India. The Indian Council of Medical Research (ICMR) reported that Covaxin has entered Phase 2 clinical trials. On October 27, 2020, the ICMR approved Covaxin for Phase 3 trial. Results of a two-dose regimen study administered to Rhesus macaques demonstrated an increase in SARS-CoV-2 specific IgG and neutralizing antibodies as well as diminished viral replication in the nasal cavity, throat, and lungs [44]. According to the trial principal investigator, initial results from the first fifty participants who received the vaccine seem to be promising. In addition, according to Bharat Biotech, the first two phases of the trial did not demonstrate any major adverse events [45]. The proposed distribution for this vaccine is February 2021, according to an ICMR scientist who spoke with Reuters.

\section{COVID-19 vaccines under clinical trials}

Some of the potential CVCs that are in Phase 3 clinical trials and might get EUA approval are described below. The other CVCs that are in clinical trials are listed in Table 2.

\section{JNJ-78436735 by Johnson \& Johnson}

Johnson \& Johnson (J\&J) is developing JNJ-78436735 (Previously as Ad26.COV2.S), using their AdVac and PERC6 systems, also used to develop the Ebola vaccine. In partnership with BARDA, J\&J has promised to invest more than \$1 billion in vaccine research and development. JNJ-78436735 is currently funded by Janssen, BARD, NAID and the Operation Warp Speed [46].

A randomized, double blind, placebo-controlled, Phase $1 / 2$ study of recombinant JNJ-78436735 in 1045 healthy subjects, 18-55 years of age, and in adults 65 years or older is ongoing. Study sites are selected in the US and Belgium (NCT04436276). The Phase 3 ENSEMBLE trial will enroll up to 60,000 subjects in the US and other countries (NCT04505722). The study protocol for the Phase 3 ENSEMBLE trial was released by J\&J on September 23, 2020. Results from the Phase $1 / 2$ study showed that a single dose of the vaccine was safe and immunogenic [47]. The results of the preclinical study showed that a single injection of JNJ-78436735 produced a strong neutralizing antibody response and offered complete or near-complete protection in bronchoalveolar lavage and nasal swabs after SARSCoV-2 administration in Rhesus macaques [48]. Another preclinical study in hamsters indicated that the vaccine protected against severe disease when tested [49].

On June 10, 2020, J\&J announced it is fast-tracking the Phase 1/2 trials. The ENSEMBLE trial was on hold pending a review of an adverse event, but $\mathrm{J} \& \mathrm{~J}$ has been cleared to resume the trial in the US and Brazil after clearance from the Independent Data Safety and Monitoring Board. J\&J also plan to start testing its vaccine in adolescents as soon as possible [46]. This vaccine candidate requires storage at $2-8{ }^{\circ} \mathrm{C}[19]$.

\section{Ad5-nCoV by CanSino Biologics}

China's CanSino Biologics has developed a recombinant novel coronavirus vaccine that incorporates the adenovirus type 5 vector (Ad5) called Ad5-nCoV. A Phase 1 clinical trial in China involving 108 participants, 18-60 years old, is active, but not recruiting. In this trial the participants will receive low, medium, and high doses of Ad5-nCoV (NCT04313127). A Phase 1 trial in China is also assessing intramuscular as well as mucosal vaccination of $\mathrm{Ad} 5-\mathrm{nCoV}$ across two doses (NCT04552366).

A Phase $1 / 2$ trial involving 696 participants in Canada is registered and not yet recruiting (NCT04398147). A Phase 2 double-blind, placebo-controlled trial with 508 participants in China (NCT04341389) is active but not recruiting. A phase $2 b$ trial in China is evaluating the safety and immunogenicity of $\mathrm{Ad} 5-\mathrm{nCoV}$ in participants who are 6 years of age and older (NCT04566770). A Phase 3 trial in Russia with 500 participants across multiple study centers is ongoing (NCT04540419). A Phase 3 trial involving 40,000 participants in countries including Pakistan, Saudi Arabia and Mexico is also ongoing (NCT04526990). A single dose of Ad5-nCoV vaccine protects against upper respiratory infection of SARSCoV-2 in ferrets. Results from the Phase 1 trial showed a humoral and immunogenic response to the vaccine. Adverse reactions such as pain (54\%), fever (46\%), fatigue (44\%), headache (39\%), and muscle pain (17\%) were reported in $83 \%$ of the patients in the low and medium dose groups and in $75 \%$ of the patients in the high dose group. Results from the Phase 2 trial showed neutralizing antibodies and specific interferon $\gamma$ enzyme-linked immunosorbent assay, at all dose levels for most of the participants. On June 25, 2020, China's Central Military Commission announced 
that Ad5-nCoV can be used in the military for a period of 1 year.

\section{NVX-CoV2373 by Novavax}

In March 2020, Novavax announced that it has manufactured a stable, prefusion protein nanoparticle vaccine candidate for COVID-19. A Phase 1/2 trial evaluating NVX-CoV2373 commenced on May 25, 2020 [50].

A randomized, observer-blinded, placebo-controlled trial involving 130 healthy participants, $18-59$ years of age, is ongoing at two sites in Australia. In this trial, patients will receive a two-dose regimen of $5 \mu \mathrm{g}$ or $25 \mu \mathrm{g}$ of NVXCoV2373 with or without Novavax's Matrix-M adjuvant (NCT04368988). A Phase 2b trial is also ongoing in South Africa, with two cohorts, group of 2,665 healthy adults and group of $240 \mathrm{HIV}$ positive adults (NCT04533399). Phase 1 trial participants who received the vaccine developed an antibody response at multiple doses. NVX-CoV2373 was also reported to be safe [51].

Novavax received the Fast Track Designation from the FDA for NVX-CoV2373 [52]. On May 11, 2020, CEPI announced that they had provided Novavax with $\$ 384$ million for the development and manufacturing of NVXCoV2373. Novavax plans to produce 1 billion doses of NVX-CoV2373 by 2021 as part of their latest acquisition of Praha Vaccines. Novavax was also awarded a $\$ 60$ million US Department of Defense contract towards manufacturing NVX-CoV2373, and another $\$ 1.6$ billion from Operation Warp Speed, if the candidate will be proved effective in clinical trials [53]. A Phase 3 trial has also begun in the United Kingdom, which will evaluate the vaccine in 10,000 participants. Novavax provided an update on October 27, 2020, of its Phase 3 trial of NVX-CoV2373 in North America, stating that the trial would commence at the end of November, roughly one month later than expected [53].

\section{COVID-19 vaccines: challenges and future prospects}

\section{Ethics}

The vaccine development effort over the globe for the COVID-19 pandemic is unprecedented, in terms of scale, speed, and supply chain. It is made possible to have a safe and effective vaccine available by the end of the year 2020, for the more vulnerable group of the population and hopefully in the first half of 2021 to all the others. Operation Warp Speed program was introduced in US to fast-track vaccine development. Moderna's mRNA vaccine and AstraZeneca/University of Oxford's AZD1222 vaccine are part of this program. Classical clinical efficacy trials of vaccines usually enroll thousands or tens of thousands of healthy participants. However, to accelerate the COVID-19 vaccine development, clinical trial phases were combined, and smaller population was enrolled. This is a noteworthy concern when the vaccine is supposed to be given to people throughout the world, there could be emergence of unknown side-effects in the larger population, which were previously not witnessed in smaller groups during short-term trials. It is important to consider whether there was an appropriate demographic consideration in the design of the clinical trials including, different races, varying age groups and those with comorbidities, as the exclusion of these may lead to unforeseen outcomes upon vaccinating these individuals when the vaccine is released for public use.

The production teams of the vaccine candidates have stated to be under pressure to develop a vaccine within few months as compared to the conventional process of $10-15$ years. With a fast-track process, post-marketing surveillance turns out to be important. Post-marketing surveillance would ensure that the vaccines are observed for side effects when administered in diverse populations. The foremost ethical concern is to find a safe and effective vaccine but at the same time not exposing clinical trial participants to avoidable risks [54].

Fast-tracking of vaccines may turn unfavorable as it could result in ineffective vaccine and may only provide partial or no immunity to some vaccinated persons. Although it is assumed that there will be thorough inspection of the vaccine candidates for safety and efficacy from the scientific community before vaccine is released for administration into the public. It is important to consider the recent small trials of the Russian vaccine Sputnik V as well as the Chinese vaccine candidates. Both Russia and China have begun the mass rollout of state-sponsored vaccine candidates with limited data. In the perspective of a public health emergency of international concerns, such shortened regulatory pathways and fast-tracked implementations are still commonly regarded as experimental interventions and are unique. However, to preserve public trust in vaccines, it is vital that complete transparency in all facets of vaccine development is available.

Due to increased demand and limited supply of vaccines, several countries including the US, India, and Europe have decided that the vaccines will be provided first to their own citizens. However, questions are being raised concerning the ethics associated with fair allocation. Though AstraZeneca has announced a collaboration with Serum Institute of India to provide an adequate number of doses to low and middleincome countries, it will be interesting how the allocation will be done when the vaccine candidates are approved and becomes available. It is also crucial to prioritize certain groups of people for vaccine allotment including, health care workers, immunocompromised individuals, those with 
comorbidities, the elderly, and those with lower socioeconomic status to guarantee distributive justice. There are also worries that the political pressure to hasten the development and approval processes, may result in an ineffective vaccine being released to the public. Such a consequence may lead to the public being hesitant from receiving future vaccines [55].

To date, no trials for COVID-19 vaccine has focused on pregnant women, despite being deemed a vulnerable population by the US Centers for Disease Control and Prevention (CDC). Although there are unanswered questions regarding the safety and efficacy of COVID-19 vaccines in pregnant women, FDA-approved COVID-19 vaccines should not be refused to women solely based on their pregnancy or lactation status, when they otherwise meet the conditions for vaccination. Patient-provider discussions should also consider the patient's individual risk-benefit profile concerning exposure at work or at home, risk to expose other members of their household, current health status and perceived risk of COVID-19 associated impediments [56]. Pregnant women should get COVID-19 vaccine without delay, as the consequences of COVID-19 infections in pregnancy are equivalent or worse than in non-pregnant populations. There is potential for damage to not one but two lives, and females of childbearing potential may have heightened workplace exposure to SARS-CoV-2. Additionally, the ongoing vaccine trials should include pregnant women to test vaccine candidates' study safety and efficacy [57].

\section{Vaccine efficacy}

Vaccine effectiveness is described as the protection provided by immunization in a defined population. It includes both direct (vaccine-induced) and indirect (population-related) protection. The effectiveness of a vaccine is proportional to its efficacy but is also influenced by the vaccine coverage, access to healthcare centers, associated costs, and other factors not directly related to the vaccine [58]. The question is, how much efficacy is actually needed for a vaccine to be considered immunogenic? Though more research is required, preliminary research studies have revealed that efficacy of $>70 \%$ is desired to eradicate the infection. A preventative vaccine with an efficacy of $<70 \%$ will still have a major effect and may add to obliterating the virus, given proper social distancing measures. Vaccines with an efficacy below $70 \%$ may contribute to decreasing the length of infection. Another study with simulation experiments showed that to prevent a pandemic, the vaccine efficacy has to be at least $60 \%$ with $100 \%$ vaccination coverage. The vaccine efficacy threshold rises to $70 \%$ when coverage drops to $75 \%$ [59].

Phase III clinical trials are required for all vaccine candidates to demonstrate that they are effective and safe in a larger population. In addition, the majority of vaccine candidates currently in clinical trials are administered intramuscularly. Though this administration route induces a strong IgG response, which is believed to protect the lower respiratory tract, unlike natural infection, it does not initiate the secretory $\operatorname{IgA}$ responses required to protect the upper respiratory tract [11]. Thus, most vaccines will provide protection against infection of the lower respiratory tract and not induce sterilizing immunity in the upper respiratory tract. This could lead to protection from symptomatic diseases but might still allow virus spread by infected person. Thus, a vaccine that could induce sterilizing immunity in the upper respiratory tract would be preferable to stop virus spread. Live attenuated vaccines or viral vectors that can be administered intranasally, would probably also lead to a strong mucosal immune response as well as an IgG response. Alas, very few vaccines that are appropriate for intranasal administration are undergoing development and none have made it to the clinical trials yet [11].

The next ethical question is, what will be the effect of the vaccine on older individuals who are at higher risk from COVID-19? According to Sinovac's inactivated vaccine and Pfizer's mRNA vaccine, the effect of the vaccine in older individuals is less compared to younger adults. Thus, there is a need for different vaccine formulation or a booster dose to improve immune responses in older individuals [11]. The children usually show increased reactogenicity compared to adults. As many CVCs have fairly strong adverse effects, low-dose vaccines might be required for children, particularly for AdV and mRNA-based vaccines. Pfizer has considered this approach and accordingly reduced the reactogenicity of its mRNA vaccine in older adults, making it appropriate for children [11].

There is also risk of vaccine enhanced disease for inactivated vaccine candidates (VAERD) that need to be considered. The higher numbers of antibodies are unable to neutralize the virus in case of high viral load, resulting in VAERD. Furthermore, ADE has been observed with other coronaviruses including MERS-CoV and SARS-CoV and could be a risk for CVCs. ADE occurs when antibodies bind to the virus and the resulting antibody-virus complex facilitates viral entry by host macrophages instead of neutralizing the virus. However, when there is an urgent need for CVCs globally, being concerned and assessing such risks should not prevent the release of otherwise safe and effective vaccines to the public [60].

If there is an incidence of the adverse reaction, there should be programs in place to safeguard proper medical treatment and compensation is provided to affected individuals and records are kept for re-evaluating the safety of the vaccine(s). The accountable authorities should also ensure that an effective and fair policy is in place, for instances where vaccination is compulsory, so the public trust in the health care system is not risked. Pre-existing immunity to 
adenoviruses is a concern, specifically for those vaccine candidates utilizing human adenoviruses such as CanSino'Ad5 vaccine, as it may lead to a decreased immune response to the vaccine. AstraZeneca/Oxford's AZD is another adenovirus-based vaccine candidate, but instead of utilizing adenovirus derived from humans, it utilizes a genetically modified chimpanzee-derived adenovirus. This effectively eliminates the concern about pre-existing immunity and thus, averts the negative impact on the immune response generated to the vaccine [60]. Although some vaccines are approved through EUA, long-term data on vaccine safety is also crucial. The well-known case of Dengue vaccine should not be overlooked, where dengue vaccine protected individuals against virologically confirmed dengue (VCD) and severe VCD for 5 years, who had exposure to dengue prior to vaccination. There was also a higher risk of VCD and severe VCD in vaccinated individuals who were not exposed to dengue earlier [61]. Thus, to avert such obstacles after vaccination, even after EUA approval, long-term safety and efficacy data is essential.

Furthermore, if a vaccine is approved for use but subsequently it is found to be not as effective as expected in the population, it could lead to a loss of trust in the vaccines. There are reports of few adverse effects with the Pfizer vaccine (Table 3) [62-64] and these recent adverse reactions were confirmed by the Finnish Medicines Agency Filmea, Finland [65]. Thus, when an effective vaccine is launched, fewer people may be inclined to accept it, which in turn can lead to further worsening of the pandemic and a decline in the confidence in already approved and effective vaccines against infections. Hence, it is vital to building trust in the public health system by being completely transparent and reporting accurate data in a timely fashion [61]. Thus, the ideal characteristics of CVCs described by WHO are important to consider while developing vaccines (Table 3) [66, 67].

\section{Manufacturing and distribution}

Manufacturers have a valuable share in the vaccine supply chain as their credibility rest on the effectiveness of their vaccines. The risks of poorly performing supply chains are detrimental for the safety and effectiveness of the vaccines, with potential consequences for future supply in case of adverse events [68]. Manufacturers from developing countries are disparate in nature and are either privately or state-owned [68]. To ensure that the threat of COVID-19 is eliminated, it is critical that a coordinated and cooperative approach is taken. This includes collaboration between several international organizations to safeguard sufficient financing and fair distribution of the vaccine supply. The organizations such as Developing Countries Vaccine Manufacturers Network (DCVMN), The Global Alliance for Vaccines and Immunizations (GAVI), Global Vaccine Action Plan (GVAP), Coalition for Epidemic Preparedness Innovations (CEPI), COVID-19 Vaccine Global Access Facility (COVAX), Bill and Melinda Gates Foundation and WHO are working in tandem to overcome this epidemic. DCVMN is a public-health-driven alliance that represents vaccine manufacturers from developing countries engaged in research, development, manufacturing and vaccine supply for domestic and international use. They aim to protect all people against known and emerging infectious diseases [69]. The number of vaccines supplied collectively by DCVMN members in 2018-2019 was about 3.5billion

Table 3 Few mild side effects of Pfizer/BioNTech COVID-19 vaccine that should not last more than a week [60-62] and Ideal COVID-19 vaccine characteristics according to WHO [64, 65]

\begin{tabular}{ll}
\hline $\begin{array}{l}\text { Few mild side effects of (Pfizer/BioNTech) } \\
\text { COVID-19 vaccine }\end{array}$ & Ideal COVID-19 vaccine characteristics according to WHO \\
\hline Injection Site pain & An admirable safety of vaccines throughout target population No contraindications \\
Injection Site swelling & Least adverse incidents that are weak and temporary \\
Injection Site redness & Be appropriate for administrations to all target population \\
A headache & Generate protective immunity- preferably after one shot \\
Fever & Produce protective immunity quickly after 14 days \\
Chills & Vaccine with no less than 70\% efficacy \\
Tiredness & Not elicit immunopathology or evidence of antibody-enhanced disease (ADE) \\
Muscle pain & Generate protection in high risk profile peoples Deliver long term protection with both humoral \\
Joint pain & and cell-mediated immunity for no less than 12 months \\
Nausea & Booster dose requirement no less than 12 months \\
Swollen lymph nodes (lymphadenopathy) & Be rapidly produced at cost or dose that permits wide-ranging use \\
Remote chance of Severe allergic reaction & Be thermostable, to be stored at room temperature to enhance vaccine distribution and availability \\
& Be administered through non-parenteral mechanisms for ease and other logistical issues \\
\hline
\end{tabular}


doses. DCVMN is working in partnership with global health authorities, international organizations and vaccine developers to support the advancement of COVID-19 vaccines. This will allow to rapidly manufacture, fill-finish and supply needed COVID-19 vaccines. Nonetheless, details about the capability for quality control, supply chain and delivery abilities must to be closely assessed [69]. To progress the supply chain, an expert group of representatives of DCVMN prioritized three main areas as Traceability in the context of global digital health initiatives, amassing in the context of addressing vaccine shortages, stock-outs, outbreaks and epidemic prevention, and new packaging technologies. It is imperative that vaccine manufacturers are actively involved in worldwide stakeholders forums as equal partners in determining the best practices for improving the vaccine supply chain [68].

The GAVI is a global public-private partnership to ensure that individuals from emerging countries, mainly children, have access to immunizations. GAVI is also a part of the recent Global Vaccine summit, which allocated funding for COVID-19 vaccine development along with to healthcare systems of GAVI eligible countries to ensure sufficient supply for emerging countries [70]. GVAP unanimously supported by the World Health Assembly in 2012, outlined a bold strategy to improve immunization. It created a Monitoring and Evaluation/Accountability (M\&E/A) to track and drive growth. Nevertheless, there is noteworthy improvement to upsurge the visibility for immunization and the benefits of the GVAP M\&E/A framework. Only few limitations are needed to be circumvented such as the limited ownership by countries and other stakeholders leading to inadequate implementation of the strategy and poor culpability for achieving GVAP targets. It could hasten the immunization cover in pandemic situations like COVID-19 [71].

Bill and Melinda Gates Foundation have allocated \$250 million towards vaccines development and for supporting the health care systems of Sub-Saharan Africa and other emerging countries. CEPI is a foundation involved in financing vaccine development and has launched COVAX in order to allow for equal accessibility of the COVID-19 vaccine for all countries. WHO is also involved in all aspects of thwarting the COVID-19 pandemic. WHO is also recording data from vaccine candidates in its Draft Landscape of COVID-19 vaccine and periodically updates it. Additionally, cooperation from individual countries is equally crucial in the fight against COVID-19 [55].

In the past, platforms based on nucleic acids such as DNA and RNA have not resulted in a successful vaccine for human diseases and so, it is yet to be seen how mRNA vaccines that are temperature-sensitive may pose difficulties for scaling up production. Moreover, for DNA vaccines, its dependence on electroporation or an injector delivery device for vaccine administration is a probable concern. Although, electroporation is considered to be a safe procedure and is vital to generate an enhanced immune response, it can complicate the vaccine delivery [60]. The global vaccine Summit has also called for an equal allocation of vaccines whenever a vaccine is released. There is still a concern that some countries will want to secure the vaccine supply for their citizens first. An example of this is the recent stockpiling of the drug, Remdesivir, in the US. This drug is used for the treatment of patients infected with COVID-19 [60]. Swift large-scale manufacturing of vaccines still remains a challenge with loads of ambiguity to meet the demand. It is likely that two doses of vaccine will be necessary. In this case, at least a 16 billion doses will be needed to meet the worldwide demand. Various vaccines described in this article are being developed by entities that have never manufactured a vaccine. Therefore, unanticipated problems with scaling could cause setbacks. It is also not yet clear whether bottlenecks will occur in the availability of supplies including, syringes or glass vials; how vaccines will be distributed worldwide; and how rollout will occur within different countries [11].

WHO has developed the Emergency Use Assessment and Listing Procedure (EUAL) to accelerate the accessibility of vaccines required in public health emergency situations. It will monitor UN procurement agencies and Member States on the suitability for use of a particular vaccine in the framework of public health emergency, based on minimum available quality, safety and efficacy data. It will speed up the acceptance and rollout of these vaccines in member countries, specifically in low and middle income countries [72, 73]. Vaccine immunogenicity and efficacy is dependent upon how they are packaged, stored, prepared and administered. Vaccines must be kept in the proper cold chain; the cold chain must be appropriately examined; and vaccines must be used only within critical time points after removal from the cold chain or once a multi-dose vial is punctured [19].

\section{Vaccine hesitancy}

Vaccine hesitancy is defined as a delay in acceptance or denial of vaccination regardless of the accessibility of vaccination services. Vaccine hesitancy is complicated and context-specific, differing across time, place, and vaccine to vaccine. It is affected by factors such as complacency, convenience, and confidence [74]. If there is greater hesitancy, it can lead to reduced vaccine demand. However, low levels of hesitancy do not certainly mean a higher vaccine demand. The vaccine hesitancy determinants matrix illustrates the factors affecting the behavioral decision to accept, delay or reject some or all vaccines, beneath three categories namely contextual, individual and group, and vaccine/vaccinationspecific influences [74].

Protective behaviors are critical to controlling epidemics, and vaccines could be the key for COVID-19. If a COVID-19 
vaccine comes to be available, it will be a key public health strategy to reduce the overall COVID-19 burden [75]. However, the anti-vaxxers community always poses a threat and is already countering the statements by experts related to the vaccines. Misleading beliefs of anti-vaxxers and their effects overlaid the path for the nastiest measles eruption in the US in 2019. Now many peoples fear similar outcomes for COVID-19. One poll in US in May 2020, demonstrated that $14-23 \%$ of the Americans are not willing to be vaccinated, whereas another poll showed that only $49 \%$ of the Americans are willing to take the COVID-19 vaccine. Yet, another study from June 2020 , showed nearly $70 \%$ of the adults in the US would be willing to take COVID-19 vaccine, if one becomes available. Other countries like Germany and Australia too have a fair share of anti-vaxxers. Hence, there should be a strategy to improve the vaccine acceptance rate in public and to counteract vaccine hesitancy [75]. Frontline healthcare workers play a decisive role in ensuring that all age groups get the recommended immunizations, and by educating people about the importance of immunization [58]. For example, the support for mandatory influenza vaccination in Denmark was significantly less [76]. The reasons for lack of vaccine uptake included considerations by employees that they do not get sick often, the vaccine was not regarded as essential, forgetfulness, and/or lack of time. Only $37.8 \%$ were in favor of mandatory influenza vaccination [76]. Thus, educational campaigns regarding benefits offered by vaccines can be helpful.

An online survey of 566 Individuals from Chile to assess an individual's willingness-to-pay (WTP) for a hypothetical COVID-19 vaccine utilized a contingent valuation methodology. The factors that positively influenced the WTP included pre-existing chronic diseases, knowledge of COVID-19, sickness associated with COVID-19, perception of government performance, income and employment status. The factors that negatively influenced the WTP included belonging to a private health system, not adjusting to work from home with children due to quarantine, and recovery from COVID-19 associated infections. In addition, there would be costs associated with manufacturing and distribution, and the developing laboratories should be financially compensated. Thus, the WTP results from this study can serve as an incentive model for the vaccine developers [3].

The impact of immunization is measured by directly assessing the effects on the vaccinated individual, indirectly on the unvaccinated community-whether herd protection is achieved or not, the epidemiology of the pathogen like altering circulating serotypes or prevention of epidemic cycles, and the added benefits rising from the better health. Aside from the protection of the individual, the larger success of immunization is dependent on attaining a level of coverage enough to interrupt microbial (virus, bacteria, etc.) transmission. Diminished coverage is certainly linked to the resurgence in disease, with outbreaks possibly leading to substantial morbidity and loss of life. The sustained success of immunization programs is the responsibility of all involved parties including individuals, healthcare professionals, government and industry [58].

\section{Future prospects}

There are numerous unanswered questions associated with SARS-CoV-2 immunity, specifically the protective immunity. There is a necessity for different types of vaccines for differing populations such as infants and children, pregnant women, immunocompromised individuals, as a majority of the vaccines under development are targeting the healthy population i.e., 18-55 years old adults. A safe regulatory pathway must also be delineated for use of these vaccines in children, pregnant women, and immunocompromised individuals. Recent outbreaks of pertussis and measles in countries where these diseases were formerly controlled demonstrated that the success of immunization programs cannot be taken for granted. Changes that occur over decades, such as lessened compliance with immunization or modifying epidemiology of disease can overturn original assumptions about the impact of the vaccine [58]. Post-marketing surveillance should also be continued to record adverse events [65].

In order to develop a safe and effective vaccine, it is vital that pre-clinical trials are done with caution to avoid severe adverse events. Moreover, cooperation between international organizations such as the WHO, CEPI, GAVI and Bill and Melinda Gates Foundation is needed to ensure ample funding for vaccines. It is anticipated that vaccines will be available worldwide by mid-2021 to mitigate this pandemic. However, the efficacy of approved vaccines on the new mutant strains found in the United Kingdom and South Africa, are yet to be studied. The implementation of the first-generation vaccines could be achieved by pushing the nucleic acid-based priming vaccines followed by a booster dose of protein-based vaccines to rein in the mortality among high-risk communities. In parallel, more potent and efficient second-generation vaccines can be developed and manufactured to combat mutations in the virus.

Author contributions Conceptualization SK, ArG and AG. Writing-original draft preparation SK and ArG. Writing-review and editing ArG, SE, and AG. Supervision AG. Project administration AG. All authors have read and agreed to the published version of the manuscript. 
Funding This research received no external funding.

\section{Declarations}

Conflict of interest The authors declare that they no conflict of interest.

Open Access This article is licensed under a Creative Commons Attribution 4.0 International License, which permits use, sharing, adaptation, distribution and reproduction in any medium or format, as long as you give appropriate credit to the original author(s) and the source, provide a link to the Creative Commons licence, and indicate if changes were made. The images or other third party material in this article are included in the article's Creative Commons licence, unless indicated otherwise in a credit line to the material. If material is not included in the article's Creative Commons licence and your intended use is not permitted by statutory regulation or exceeds the permitted use, you will need to obtain permission directly from the copyright holder. To view a copy of this licence, visit http://creativecommons.org/licenses/by/4.0/.

\section{References}

1. Gupta A, Kashte S, Gupta M, Rodriguez HC, Gautam SS. Mesenchymal stem cells and exosome therapy for COVID-19: current status and future perspective. Hum Cell. 2020;33:907-18. https:// doi.org/10.1007/s13577-020-00407-w.

2. WHO Coronavirus Disease (COVID-19) Dashboard [Internet]. WHO (World Heal. Organ. 2021. Available from: https://covid 19. who.int/. Cited 3 Jan 2021.

3. García LY, Cerda AA. Contingent assessment of the COVID-19 vaccine. Vaccine. 2020;38:5424-9.

4. Khuroo MS. Chloroquine and hydroxychloroquine in coronavirus disease 2019 (COVID-19). Facts, fiction and the hype: a critical appraisal. Int J Antimicrob Agents. 2020;56:106101.

5. Draft Landscape of COVID-19 candidate vaccines-29 December 2020 [Internet]. World Heal. Organ. 2020, p. 12. Available from: www.who.int/publications/m/item/draft-landscape-of-covid-19candidate-vaccines. Cited 30 Dec 2020.

6. Dai X, Xiong Y, Li N, Jian C. Vaccine types. In; Vaccines-the history and future. IntechOpen. 2001, pp 1-9.

7. Khuroo MS, Khuroo M, Khuroo MS, Sofi AA, Khuroo NS COVID-19 vaccines: a race against time in the middle of death and devastation. J Clin Exp Hepatol. 2020. https://doi. org/10.1016/j.jceh.2020.06.003.

8. Kaur SP, Gupta V. COVID-19 vaccine: a comprehensive status report. Virus Res. 2020;288:198114. https://doi.org/10.1016/j. virusres.2020.198114

9. Ou X, Liu Y, Lei X, Li P, Mi D, Ren L, et al. Characterization of spike glycoprotein of SARS-CoV-2 on virus entry and its immune cross-reactivity with SARS-CoV. Nat Commun. 2019;11:1620. https://doi.org/10.1038/s41467-020-15562-9.

10. Cunningham AL, Garçon N, Leo O, Friedland LR, Strugnell $\mathrm{R}$, Laupèze $\mathrm{B}$, et al. Vaccine development: from concept to early clinical testing. Vaccine. 2016;34:6655-64. https://doi. org/10.1016/j.vaccine.2016.10.016.

11. Krammer F. SARS-CoV-2 vaccines in development. Nature. 2020;586:516-27. https://doi.org/10.1038/s41586-020-2798-3.

12. Emergency Use Authorization for Vaccines to Prevent COVID-19 Guidance for Industry [Internet]. Food Drug Adm. 2020. Available from: https://www.fda.gov/regulatory-information/searc h-fda-guidance-documents/emergency-use-authorization-vacci nes-prevent-covid-19. Cited 14 Dec 2020.
13. Pallesen J, Wang N, Corbett KS, Wrapp D, Kirchdoerfer $\mathrm{RN}$. Immunogenicity and structures of a rationally designed prefusion MERS-CoV spike antigen. Proc Natl Acad Sci. 2017;114:E7348-57.

14. FDA Takes Key Action in Fight Against COVID-19 By Issuing Emergency Use Authorization for First COVID-19 Vaccine [Internet]. FDA. 2020. Available from: https://www.fda.gov/news-event s/press-announcements/fda-takes-key-action-fight-against-covid -19-issuing-emergency-use-authorization-first-covid-19. Cited 15 Dec 2020.

15. WHO issues its first emergency use validation for a COVID-19 vaccine and emphasizes need for equitable global access [Internet]. World Health Organ. Available from: www.who.int/news/ item/31-12-2020-who-issues-its-first-emergency-use-validation -for-a-covid-19-vaccine-and-emphasizes-need-for-equitable-globa 1-access. Cited 01 Jan 2021.

16. Pfizer. Aa phase 1/2/3, placebo-controlled, randomized, observerblind, dose-finding study to evaluate the safety, tolerability, immunogenicity, and efficacy of sars-cov- 2 rna vaccine candidates against covid-19 in healthy individuals. 2020. p 1-146. https://pfepfizercom-d8-prod.s3.amazonaws.com/2020-11/C4591001_Clini cal_Protocol_Nov2020.pdf.

17. Kitchin N, Absalon J, Gurtman A, Lockhart S, Neuzil K, Mulligan MJ, et al. Safety and immunogenicity of two RNA-based covid-19 vaccine candidates. N Engl J Med. 2020;383:2439-50.

18. Mulligan MJ, Lyke KE, Kitchin N, Absalon J, Gurtman A, Lockhart S, et al. Phase I / II study of COVID-19 RNA vaccine BNT162b1 in adults. Nature. 2020;586:589-93. https://doi. org/10.1038/s41586-020-2639-4.

19. Holm M, Poland G. Critical aspects of packaging, storage, preparation, and administration of mRNA and adenovirus-vectored COVID-19 vaccines for optimal efficacy. Vaccine. 2020. https:// doi.org/10.1016/j.vaccine.2020.12.017.

20. Moderna's COVID-19 vaccine candidate meets its primary efficacy endpoint in the first interim analysis of the phase $3 \mathrm{COVE}$ study [Internet]. 2020. Available from: https://investors.moder natx.com/news-releases/news-release-details/modernas-covid -19-vaccine-candidate-meets-its-primary-efficacy. Cited 17 Nov 2020.

21. Coler RN, Mccullough MP, Chappell JD, Denison MR, Stevens LJ, Morabito KM, et al. An mRNA vaccine against SARS-CoV-2 — preliminary report. N Engl J Med. 2020;383:1920-31.

22. Makhene M, Chappell JD, Denison MR, Stevens LJ, Pruijssers AJ, Mcdermott AB, et al. Safety and immunogenicity of SARSCoV-2 mRNA-1273 vaccine in older adults. N Engl J Med 2020;383:2427-38.

23. Corbett KS, Edwards DK, Leist SR, Abiona OM, Boyoglu-barnum $\mathrm{S}$, Gillespie RA, et al. SARS-CoV-2 mRNA vaccine design enabled by prototype pathogen preparedness. Nature. 2020;586:56771. https://doi.org/10.1038/s41586-020-2622-0.

24. Flach B, Connell SO, Bock KW, Minai M, Nagata BM, Andersen $\mathrm{H}$, et al. Evaluation of the mRNA-1273 vaccine against SARSCoV-2 in nonhuman primates. N Engl J Med. 2020;383:1544-55.

25. Moderna Announces Phase 3 COVE Study of mRNA Vaccine Against COVID-19 (mRNA-1273) Begins [Internet]. 2020. Available from: https://investors.modernatx.com/news-releases/newsrelease-details/moderna-announces-phase-3-cove-study-mrnavaccine-against-covid. Cited 17 Nov 2020.

26. AstraZeneca's COVID-19 vaccine authorised for emergency supply in the UK [Internet]. AstraZeneca. Available from: https:// www.astrazeneca.com/media-centre/press-releases/2020/astra zenecas-covid-19-vaccine-authorised-in-uk.html. Cited 30 Dec 2020.

27. India's drugs experts approve AstraZeneca, local COVID vaccines [Internet]. Reuters. 2021. Available from: https://www. reuters.com/article/health-coronavirus-india-vaccine/indias-drugs 
-experts-approve-astrazeneca-local-covid-vaccines-idUSKBN297 07B. Cited 3 Jan 2021.

28. Doremalen N Van, Lambe T, Spencer A, Belij-rammerstorfer S, Purushotham JN, Port JR, et al. ChAdOx $1 \mathrm{nCoV}-19$ vaccination prevents SARS-CoV-2 pneumonia in rhesus macaques. Nature. 2020;586:578-82.

29. Graham SP, Mclean RK, Spencer AJ, Belij-Rammerstorfer S, Wright D, Ulaszewska M, et al. Evaluation of the immunogenicity of prime-boost vaccination with the replication-deficient viral vectored COVID-19 vaccine candidate ChAdOx $1 \mathrm{nCoV}-19$. NPJ Vaccines. 2020;5:1-6. https://doi.org/10.1038/s41541-020-00221 -3 .

30. Folegatti PM, Ewer KJ, Aley PK, Angus B, Becker S, Belij-rammerstorfer $\mathrm{S}$, et al. Safety and immunogenicity of the ChAdOx1 nCoV-19 vaccine against SARS-CoV-2: a preliminary report of a phase 1 / 2, single-blind, randomised controlled trial. Lancet. 2020;396:467-78.

31. Clinical study protocol - amendment 2 AZD1222 - D8110C00001. A phase III randomized, double-blind, placebo-controlled multicenter study in adults to determine the safety, efficacy, and immunogenicity of AZD1222, a non-replicating ChAdOx1 vector vaccine, for the prevention of COVID-19. AstraZeneca. 2020. p. 1-111. https://astrazenecagrouptrials.pharmacm.com/ST/Submi ssion/View?id=26198.

32. Sinovac's Coronavirus vaccine candidate approved for emergency use in China [Internet]. Reuters. 2020. Available from: https:// www.reuters.com/article/us-health-coronavirus-china-vaccines/ sinovacs-coronavirus-vaccine-candidate-approved-for-emergencyuse-in-china-source-idUSKBN25O0Z3. Cited 15 Dec 2020.

33. Gao Q, Bao L, Mao H, Wang L, Xu K, Yang M, et al. Development of an inactivated vaccine candidate for SARS-CoV-2. Science. 2020;81:77-81.

34. Zhang Y, Zeng G, Pan H, Li C, Hu Y, Chu K, et al. Safety, tolerability, and immunogenicity of an inactivated SARS-CoV-2 vaccine in healthy adults aged 18-59 years. Lancet Infect Dis. 2020. https://doi.org/10.1016/S1473-3099(20)30843-4.

35. Brazil's National Health Surveillance Agency Authorizes Resumption of the Phase III Clinical Trial of CoronaVac ${ }^{\mathrm{TM}}$ [Internet]. 2020. Available from: http://www.sinovac.com/?optio nid=754\&auto_id=915. Cited 18 Nov 2020.

36. Taylor A. China's COVID vaccines are already being distributed. But how do they work, and where are they up to in trials? [Internet]. Conversat. 2020. Available from: https://theconversation .com/chinas-covid-vaccines-are-already-being-distributed-buthow-do-they-work-and-where-are-they-up-to-in-trials- 151589. Cited 15 Dec 2020.

37. Xia S, Duan K, Zhang Y, Zhao D, Zhang H, Xie Z, Yang Y. Effect of an inactivated vaccine against SARS-CoV-2 on safety and immunogenicity outcomes interim analysis of 2 randomized clinical trials. JAMA. 2020;324:951-60.

38. Babira VF, Borisevich SV, Naroditsky BS, Gintsburg AL. Safety and immunogenicity of an rAd26 and rAd5 vector-based heterologous prime-boost COVID-19 vaccine in two formulations: two open, non-randomised phase 1/2 studies from Russia. Lancet. 2020;396:887-97. https://doi.org/10.1016/S0140-6736(20)31866 $-3$.

39. Sputnik V. The first registered vaccine against COVID-19. [Internet]. 2020. Available from: https://sputnikvaccine.com/about -vaccine/. Cited 19 Nov 2020.

40. Wang H, Zhang Y, Huang B, Gao GF, Tan W, Yang X. Development of an inactivated vaccine candidate, BBIBP-CorV, with potent protection against SARS-ll article development of an inactivated vaccine candidate, BBIBP-CorV, with potent protection against SARS-CoV-2. Cell. 2020;182:713-21.

41. Xia S, Zhang Y, Wang Y, Wang H, Yang Y, Gao GF, et al. Safety and immunogenicity of an inactivated SARS-CoV-2 vaccine,
BBIBP-CorV: a randomised, double-blind, placebo-controlled, phase 1/2 trial. Lancet Infect Dis. 2020. https://doi.org/10.1016/ S1473-3099(20)30831-8.

42. Russia approves second COVID-19 vaccine after preliminary trials [Internet]. Reuters. 2020. Available from: https://in.reute rs.com/article/us-health-coronavirus-russia-vaccine-idINKBN26Z 1T3. Cited 15 Dec 2020.

43. Russia begins mass trials of second coronavirus vaccine [Internet]. Reuters. 2020. Available from: https://www.reuters.com/article/ health-coronavirus-russia-cases/update-1-russia-begins-mass-trial s-of-second-coronavirus-vaccine-idUSL1N2IG0HG?edition-redir ect=ca. Cited 15 Dec 2020.

44. Yadav P, Mohandas S. Remarkable immunogenicity and protective e cacy of BBV152, an inactivated SARS-CoV-2 vaccine in rhesus macaques [Internet]. Res. Sq. 2020. p. 1-17. Available from: https://www.researchsquare.com/article/rs-65715/v1. Cited 19 Nov 2020.

45. COVAXINTM-India's First indigenous COVID-19 Vaccine [Internet]. 2020. Available from: https://www.bharatbiotech.com/ covaxin.html. Cited 18 Nov 2020

46. Johnson \& Johnson Initiates Pivotal Global Phase 3 Clinical Trial of Janssen's COVID-19 Vaccine Candidate [Internet]. 2020. Available from: https://www.jnj.com/johnson-johnson-initiatespivotal-global-phase-3-clinical-trial-of-janssens-covid-19-vacci ne-candidate. Cited 20 Nov 2020.

47. Sadoff J, Le Gars M, Shukarev G, Heerwegh D, Truyers C, de Groot AM, Berghmans PJ. Safety and immunogenicity of the Ad26.COV2.S COVID-19 vaccine candidate: interim results 2 of a phase $1 / 2 \mathrm{a}$, double-blind, randomized, placebo-controlled trial. MedRxiv. 2020;94:1-28.

48. Tostanoski LH, He X, Martinez DR, Rutten L, Bos R, Van MD, et al. Single-shot Ad26 vaccine protects against SARS-CoV-2 in rhesus macaques. Nature. 2020;586:583-8. https://doi.org/10.1038/ s41586-020-2607-z.

49. Tostanoski LH, Wegmann F, Martinot AJ, Loos C, Mcmahan K, Mercado NB, et al. Ad26 vaccine protects against SARS-CoV-2 severe clinical disease in hamsters. Nat Med. 2020;26:1694-700. https://doi.org/10.1038/s41591-020-1070-6.

50. Novavax Awarded Funding from CEPI for COVID-19 Vaccine Development [Internet]. 2020. Available from: https://ir.novav ax.com/news-releases/news-release-details/novavax-awardedfunding-cepi-covid-19-vaccine-development. Cited 20 Nov 2020.

51. Keech C, Albert G, Cho I, Robertson A, Reed P, Neal S, et al. Phase 1-2 trial of a SARS-CoV-2 recombinant spike protein nanoparticle vaccine. N Engl J Med. 2020;383:1-13.

52. Novavax COVID-19 Vaccine Granted Fast Track Designation by U.S. FDA [Internet]. 2020. Available from: https://ir.novav ax.com/news-releases/news-release-details/novavax-covid-19vaccine-granted-fast-track-designation-us-fda. Cited 20 Nov 2020.

53. Novavax Provides Phase 3 COVID-19 Vaccine Clinical Development Update [Internet]. 2020. Available from: https://ir.novav ax.com/news-releases/news-release-details/novavax-providesphase-3-covid-19-vaccine-clinical-development. Cited 20 Nov 2020.

54. Grady C. Ethics of vaccine research. Nat Immunol. 2004;5:465-8.

55. COVAX announces additional deals to access promising COVID19 vaccine candidates; plans global rollout starting Q1 2021 [Internet]. Glob. Alliance Vaccines Immunizations. 2020. Available from: https://www.gavi.org/news/media-room/covax-annou nces-additional-deals-access-promising-covid-19-vaccine-candi dates-plans. Cited 23 Dec 2020.

56. Craig AM, Hughes BL, Swamy GK. COVID-19 Vaccines in Pregnancy. Am J Obstet Gynecol MFM. 2021. https://doi. org/10.1016/j.ajogmf.2020.100295.

57. Krubiner CB, Faden RR, Karron RA, Little MO, Lyerly AD, Abramson JS, et al. Pregnant women and vaccines against 
emerging epidemic threats: ethics guidance for preparedness, research, and response. Vaccine. 2021;39:85-120. https://doi. org/10.1016/j.vaccine.2019.01.011.

58. Doherty M, Buchy P, Standaert B, Giaquinto C, Cohrs DP. Vaccine impact: benefits for human health. Vaccine. 2016;34:670714. https://doi.org/10.1016/j.vaccine.2016.10.025.

59. Bartsch SM, Shea KJO, Ferguson MC, Bottazzi ME, Wedlock PT, Strych U, et al. Vaccine efficacy needed for a COVID-19 Coronavirus vaccine to prevent or stop an epidemic as the sole intervention. Am J Prev Med. 2020;59:493-503. https://doi.org/10.1016/j. amepre.2020.06.011.

60. Sharma O, Sultan AA, Ding H, Triggle CR. A review of the progress and challenges of developing a vaccine for COVID-19. Front Immunol. 2021;11:1-17.

61. Savarino S, Zambrano B, Moureau A, Khromava A, Moodie Z, Westling T, et al. Effect of Dengue serostatus on Dengue vaccine safety and efficacy. N Engl J Med. 2018;379:327-40.

62. Coronavirus (COVID-19) vaccine [Internet]. NHS. 2020. Available from: https://www.nhs.uk/conditions/coronavirus-covid-19/ coronavirus-vaccination/coronavirus-vaccine/. Cited 28 Dec 2020.

63. What to Expect after Getting a COVID-19 Vaccine [Internet]. Centers Dis. Control Prev. 2020. Available from: https://www.cdc. gov/coronavirus/2019-ncov/vaccines/expect/after.html. Cited 28 Dec 2020.

64. Fact sheet for recipients and caregivers, Emergency Use Authorization (EUA) of the Pfizer-Biontech COVID-19 vaccine to prevent Coronavirus disease 2019 (COVID-19) in individuals 16 years of age and older [Internet]. FDA. 2020. Available from: https://www. fda.gov/media/144414/download. Cited 28 Dec 2020.

65. Finland reports first adverse reaction to Coronavirus vaccine [Internet]. Yle. 2021. Available from: https://yle.fi/uutiset/osast o/news/finland_reports_first_adverse_reaction_to_coronaviru s_vaccine/11722156. Cited 3 Jan 2021.

66. WHO target product profiles for COVID-19 vaccines version 3-29 April 2020. WHO World Heal Organ. 2020, p. 1-7. https:// www.who.int/publications/m/item/who-target-product-profilesfor-covid-19-vaccines.

67. Poland GA, Ovsyannikova IG, Crooke SN, Kennedy RB. SARSCoV-2 vaccine development: current status. Mayo Clin Proc. 2020;95:2172-88. https://doi.org/10.1016/j.mayocp.2020.07.021.

68. Jarrett S, Yang L, Pagliusi S. Roadmap for strengthening the vaccine supply chain in emerging countries: manufacturers, perspectives. Vaccine. 2020;5:100068. https://doi.org/10.1016/j. jvacx.2020.100068.

69. Pagliusi S, Jarrett S, Hayman B, Kreysa U, Prasad SD, Reers M. Emerging manufacturers engagements in the COVID A 19 vaccine research, development and supply. Vaccine. 2020;38:5418-23.

70. GAVI-The Global Alliance for Vaccines and Immunizations [Internet]. WHO Glob. Heal. Work. Alliance. 2020. Available from: www.who.int/workforcealliance/members_partners/membe r_list/gavi/en/. Cited 23 Dec 2020.

71. Hwang A, Veira C, Malvolti S, Cherian T, Macdonald N, Steffen $\mathrm{C}$, et al. Global vaccine action plan lessons learned II: stakeholder perspectives. Vaccine. 2020;38:5372-8. https://doi.org/10.1016/j. vaccine.2020.05.048.

72. Emergency Use Assessment and Listing Procedure (EUAL) for candidate vaccines for use in the context of a public health emergency [Internet]. WHO (World Health Organ. 2015. p. 1-10. Available from: https://www.who.int/medicines/news/EUALvaccines_7July2015_MS_(Updated_notes-disclaimers_21Aug 2018).pdf?ua=1. Cited 14 Dec 2020.

73. Emergency use listing procedure for vaccines [Internet]. WHO (World Health Organ. 2020. Available from: https://www.who.int/ teams/regulation-prequalification/eul/eulvaccines. Cited $14 \mathrm{Dec}$ 2020.

74. Macdonald NE, Group W. Vaccine hesitancy: definition, scope and determinants. Vaccine. 2015;33:4161-4.

75. Reiter PL, Pennell ML, Katz ML. Acceptability of a COVID19 vaccine among adults in the United States: how many people would get vaccinated ? Vaccine. 2021;38:6500-7. https://doi. org/10.1016/j.vaccine.2020.08.043.

76. Von LM, Nordmann T, Eltvedt A, Bybeck A, Yde A, Poulsen A. Self-reported immunity and opinions on vaccination of hospital personnel among paediatric healthcare workers in Denmark. Vaccine. 2020;38:6570-7. https://doi.org/10.1016/j.vacci ne.2020.08.010

Publisher's Note Springer Nature remains neutral with regard to jurisdictional claims in published maps and institutional affiliations. 